\title{
CORONAVIRUS
}

\section{A SARS-CoV-2 ferritin nanoparticle vaccine elicits protective immune responses in nonhuman primates}

\begin{abstract}
M. Gordon Joyce ${ }^{1,2 *}$, Hannah A. D. King',2,3, Ines Elakhal-Naouar,4, Aslaa Ahmed ${ }^{5}$, Kristina K. Peachman ${ }^{4}$, Camila Macedo Cincotta ${ }^{2,4}$, Caroline Subra ${ }^{1,2,3}$, Rita E. Chen ${ }^{6,7}$, Paul V. Thomas ${ }^{1,2}$, Wei-Hung Chen ${ }^{1,2}$, Rajeshwer $^{1,2}$ S. Sankhala ${ }^{1,2}$, Agnes Hajduczki ${ }^{1,2}$, Elizabeth J. Martinez ${ }^{1,2}$, Caroline E. Peterson',2, William C. Changi,2, Misook Choe $^{1,2}$, Clayton Smith ${ }^{8}$, Parker J. Lee ${ }^{1,2}$, Jarrett A. Headley ${ }^{1,2}$, Mekdi G. Taddese ${ }^{1,2}$, Hanne A. Elyard ${ }^{9}$, Anthony Cook $^{9}$, Alexander Anderson ${ }^{3,10}$, Kathryn McGuckin Wuertz ${ }^{3}$, Ming Dong, ${ }^{1,2,3}$, Isabella Swafford ${ }^{1,2,3}$, James Brett Case $^{6}$, Jeffrey R. Currier ${ }^{5}$, Kerri G. Lal ${ }^{1,2,3}$, Sebastian Molnar ${ }^{1,2,3}$, Manoj S. Nair ${ }^{11}$, Vincent Dussupt ${ }^{1,2,3}$, Sharon P. Daye $^{12}$, Xiankun Zeng, ${ }^{13}$ Erica K. Barkei ${ }^{14}$, Hilary M. Staples ${ }^{15}$, Kendra Alfson, ${ }^{15}$ Ricardo Carrion $^{15}$, Shelly . Krebs $^{1,2,3}$, Dominic Paquin-Proulx ${ }^{1,2,3}$, Nicos Karasavva ${ }^{2,4}$, Victoria R. Polonis ${ }^{3}$, Linda L. Jagodzinski ${ }^{4}$, Mihret F. Amare $^{1,2}$, Sandhya Vasan ${ }^{1,2,3}$, Paul T. Scott', Yaoxing Huang11, David D. Ho ${ }^{11}$, Natalia de Val ${ }^{8}$, Michael S. Diamond $^{6,7,16}$, Mark G. Lewis ${ }^{9}$, Mangala Rao ${ }^{3}$, Gary R. Matyas ${ }^{3}$, Gregory D. Gromowski ${ }^{5}$, Sheila A. Peel ${ }^{4}$, Nelson L. Michael ${ }^{12}$, Diane L. Bolton, ${ }^{1,2,3}$ and Kayvon Modjarrad ${ }^{1 *}$

1Emerging Infectious Diseases Branch, Walter Reed Army Institute of Research (WRAIR), Silver Spring MD 20910, USA. ${ }^{2}$ Henry M. Jackson Foundation for the Advancement of Military Medicine, Bethesda MD 20817, USA. ${ }^{3}$ US Military HIV Research Program, WRAIR, Silver Spring MD 20910, USA. " Diagnostics and Countermeasures Branch, WRAIR, Silver Spring MD 20910, USA. ${ }^{5}$ Viral Diseases Branch, WRAIR, Silver Spring MD 20910, USA. ${ }^{6}$ Department of Medicine, Washington University, St. Louis, M0 63130, USA. ${ }^{7}$ Department of Pathology \& Immunology, Washington University, St. Louis, M0 63130, USA. ${ }^{8}$ Center for Molecular Microscopy, Center for Cancer Research, National Cancer Institute, National Institutes of Health, Frederick, MD 21702, USA. ${ }^{9}$ Bioqual, Rockville, MD 20850, USA. ${ }^{10}$ Oak Ridge Institute of Science and Education, Oak Ridge, TN 37830, USA. "1Diamond AIDS Research Center, Columbia University Vagelos College of Physicians and Surgeons, New York, NY 10032, USA. ${ }^{12}$ Center for Infectious Diseases Research, WRAIR, Silver Spring MD 20910, USA. ${ }^{13}$ Division of Pathology, United States Army Medical Research Institute of Infectious Diseases, Frederick, MD 21702, USA. ${ }^{14}$ Veterinary Medicine Branch, WRAIR, Silver Spring MD 20910, USA. ${ }^{15}$ epartment of Virology and Immunology, Texas Biomedical Research Institute, San Antonio TX 78227, USA. ${ }^{16}$ Department of Molecular Microbiology, Washington University, St. Louis, M0 63130, USA.

*Corresponding authors. Email: kayvon.modjarrad.civ@mail.mil; gjoyce@eidresearch.org
\end{abstract}

The emergence of severe acute respiratory syndrome coronavirus 2 (SARS-CoV-2) variants stresses the continued need for next-generation vaccines that confer broad protection against coronavirus disease 2019 (COVID-19). We developed and evaluated an adjuvanted SARS-CoV-2 spike ferritin nanoparticle (SpFN) vaccine in nonhuman primates. High-dose $(50 \mu g) \mathrm{SpFN}$ vaccine, given twice 28 days apart, induced a Th1biased CD4 T cell helper response and elicited neutralizing antibodies against SARS-CoV-2 wild-type and variants of concern, as well as against SARS-CoV-1. These potent humoral and cell-mediated immune responses translated into rapid elimination of replicating virus in the upper and lower airways and lung parenchyma of nonhuman primates following high-dose SARS-CoV-2 respiratory challenge. The immune response elicited by SpFN vaccination and resulting efficacy in nonhuman primates supports the utility of $\mathrm{SpFN}$ as a vaccine candidate for SARS-causing betacoronaviruses.

\section{INTRODUCTION}

The coronavirus disease 2019 (COVID-19) pandemic, caused by severe acute respiratory syndrome coronavirus 2 (SARS-CoV-2), has reached a milestone with the emergency use authorization, approval, and increasing availability of efficacious vaccines (1). Successes in rapid coronavirus vaccine development, however, have been tempered by the rise of viral variants of concern (VOCs) (2). The accelerating frequency with which variants are emerging raises the specter that host selective pressures may drive the evolution of mutants to escape vaccine-elicited immunity (3). This concern, coupled with stringent cold-chain requirements for product stability and high unit costs for some vaccine platforms (4), justifies the continued development of cost-effective, thermo-stable vaccines that match currently authorized and approved vaccines in safety and efficacy, and are also effective against a wide range of circulating variants and evolving strains, as well as species that may arise from zoonotic reservoirs in the future.

Self-assembling protein nanoparticle vaccines offer the advantage of multivalent antigen presentation, a property previously shown to augment immunogenicity over monovalent immunogens (5-7). Ferritin is a naturally occurring, ubiquitous, iron-carrying protein that self-oligomerizes into a 24-unit spherical particle (8). The three-fold axis symmetry of the resulting polymer makes it conducive to conjugation and antigen display of trimeric glycoproteins, such as SARSCoV-2 spike protein. Ferritin has been evaluated as a vaccine 
platform for several pathogens (9-11), most notably influenza, for which it has demonstrated immune potency and breadth $(12,13)$. As such, ferritin vaccines have advanced to phase 1 clinical trials as a strategy to target multiple influenza strains $(14,15)$.

The prefusion-stabilized form of the spike protein is the basis for most major SARS-CoV-2 vaccine candidates $(16,17)$. Although a correlate of protection from COVID-19 has not been conclusively defined, there is mounting evidence that neutralizing, and some fraction of non-neutralizing, antibodies against spike protein are necessary, if not sufficient, to confer protective immunity $(18,19)$. The most potent neutralizing antibodies are directed against the spike protein receptor-binding domain (RBD), which mediates attachment to the primary host cell receptor, angiotensin converting enzyme (ACE2). Our prior assessment of a SARS-CoV-2 spike protein ferritin nanoparticle $(\mathrm{SpFN})$ vaccine candidate, coformulated with a liposomal adjuvant, has demonstrated potent immunogenicity and protection against SARS-CoV-2 infection in mouse models (20). These data have provided a basis for evaluating SpFN immunogenicity and efficacy against viral replication and pathology in the airways and lungs of nonhuman primates (NHP), a standard model for preclinical evaluation of SARS-CoV-2 vaccines (21).

\section{RESULTS \\ A SARS-CoV-2 nanoparticle vaccine was designed and administered to NHPs.}

The spike ferritin nanoparticle $(\mathrm{SpFN})$ vaccine was designed as a ferritin-fusion recombinant protein for expression as a nanoparticle, and has been described in detail previously (20). Briefly, the spike protein sequence was derived from the Wuhan-Hu-1 genome sequence (GenBank accession number: MN908947.3). The spike protein ectodomain was modified to introduce two proline residues (K986P, V987P) and removal of the furin cleavage site (RRAS to GSAS), as previously described (16). To stabilize spike protein trimer formation on the ferritin molecule, the heptad repeat between stem hinge 1 and 2 region (residues 1140 - 1161) was mutated to increase the coiled coil interactions. An adjuvant, Army Liposome Formulation containing QS21 (ALFQ), was mixed with the SpFN vaccine at room temperature and administered to animals within four hours of mixing. Briefly, ALFQ is a liposome formulation comprising saturated phospholipids, dimyristoyl phosphatidylcholine (DMPC) and dimyristoyl phosphatidylglycerol (DMPG); cholesterol, and two adjuvants, synthetic monophosphoryl lipid A (3D- PHAD) (200 $\mu \mathrm{g} /$ dose) and QS$21(100 \mu \mathrm{g} /$ dose $)$ in a molar ratio of 9:1:12.2:0.114:0.044 (22). QS-21 is a triterpenoid glycoside saponin derived from the bark of the Quillaja saponaria (soap bark) tree, found in Chile. QS-21 binds irreversibly to cholesterol in the liposomes and abrogates the toxicity seen with free QS-21 (23).

In this study, 32 male and female specific-pathogen-free, research-naïve, Chinese-origin rhesus macaques (age 3 to 7 years) were distributed on the basis of age, weight and sex into 4 cohorts of 8 animals (table S1). Animals were vaccinated intramuscularly with either 50 or $5 \mu \mathrm{g}$ of $\mathrm{SpFN}$ formulated with ALFQ or $1 \mathrm{ml}$ of phosphate buffered saline (PBS) in the anterior proximal quadriceps muscle. Animals were vaccinated on alternating sides with each dose in the series. Immunizations were administered twice, 4 weeks apart, or once, 4 weeks prior to challenge (fig. S1). Animals were challenged with $1 \times 10^{6} 50 \%$ tissue culture infective dose $\left(\mathrm{TCID}_{50}\right.$ ) of SARS-CoV-2 (SARS-Related Coronavirus 2, Isolate USA-WA1/2020) administered simultaneously by the intratracheal $(1.0 \mathrm{ml})$ and intranasal $(0.5 \mathrm{ml}$ per nostril) routes.

SpFN vaccination elicits neutralizing antibody responses in NHPs.

We measured longitudinal antibody responses in animals, after each vaccination and after viral challenge. Total binding to SARS-CoV-2 prefusion stabilized spike protein (S-2P) (16) increased from baseline to an area under the curve (AUC) of 679,213 and 1,646,288 at 4 weeks after two vaccinations with 5 and $50 \mu \mathrm{g}$ of SpFN, respectively (Fig. 1A). Vaccination with a single $50 \mu \mathrm{g}$ dose resulted in a 4-week AUC of 621,605. Binding responses were unchanged in vaccinated groups after viral challenge; in contrast, unvaccinated controls had a 200fold rise (Fig. 1A). Neutralization was tested using spike protein pseudotyped human immunodeficiency virus (HIV). Two-doses of $5 \mu \mathrm{g}$ or $50 \mu \mathrm{g}$ SpFN elicited reciprocal $50 \%$ inhibitory dilution ( $\mathrm{ID}_{50}$ ) pseudovirus neutralizing antibody geometric mean titers (GMT) of 22,405 and 52,773, respectively, two weeks after second vaccination, and plateaued at 12,171 and 22,527, two weeks later (Fig. 1B). Administration of a single dose of $50 \mu \mathrm{g}$ SpFN elicited a peak GMT of 4,063. Authentic virus neutralization activity mirrored group differences seen in the pseudovirus assay, but at slightly lower values (Fig. 1C).

We performed functional assessments of binding antibody responses by measuring the ability of serum samples to inhibit binding of RBD to the ACE2 receptor. Binding inhibition in the $5 \mu \mathrm{g}$ and $50 \mu \mathrm{g}$ vaccinated animals exceeded that among unvaccinated controls by a factor of 224 and 998 , respectively (Fig. 1D). ACE2 competition in the single $50 \mu \mathrm{g}$ dose group was 291 times higher than controls. We compared neutralizing antibody responses elicited by the vaccine against a panel of convalescent plasma samples with the same pseudovirus neutralization assay. We found that two doses of either SpFN dose elicited neutralizing activity that was an order of magnitude higher than that of the convalescent serum samples $(\mathrm{p}<0.01$, Fig. $1 \mathrm{E})$.

We used orthogonal approaches to assess binding antibody specificities to the spike S1 subunit domains. RBD and $\mathrm{S}-2 \mathrm{P}$ binding recapitulated results of the ACE2 binding inhibition assay (fig. S2). Serum binding to the N-terminal 
domain (NTD), which may be a marker of additional protection through both neutralizing activity and non-neutralizing effector functions (24), were 500-fold higher compared to baseline, across vaccine groups (fig. S3). We assessed the strength of RBD binding by biolayer interferometry, finding an increasing antibody on-rate association response throughout follow-up (fig. S4). Given the potential importance of auxiliary antibody functions for protection $(25,26)$, we assessed a suite of Fc-mediated antibody effector functions, including opsonization, antibody-dependent complement deposition (ADCD), antibody-dependent cellular phagocytosis (ADCP), antibody-dependent neutrophil phagocytosis (ADNP) and trogocytosis (a measure of antigen transfer) (27). All activity peaked at week 6 and was highest in the two-dose $50 \mu \mathrm{g} \mathrm{SpFN}$ group (fig. S5).

\section{SpFN vaccination elicits spike protein-specific T cell responses in NHPs.}

Helper CD4 T cell (Th) responses are important for respiratory virus vaccine development, given the theoretical concern and precedent for vaccine-associated enhanced respiratory disease and its association with a Th2-biased response (28). We focused our assessment of cell-mediated immunity on canonical cytokines expressed by Th1 (interferon (IFN)- $\gamma$, tumor necrosis factor (TNF)- $\alpha$, interleukin (IL)-2) and Th2 (IL-4, IL-13) CD4 T cells. Robust Th1 responses were observed 4 weeks after second vaccination in all vaccinated groups, except one animal in the $50 \mu \mathrm{g}$ single-dose group (Fig. $2 \mathrm{~A})$. Th1 responses were polyfunctional and variable but consistently high at week 8 , ranging from $0.2 \%$ to $17 \%$. Th2 and CD8 $\mathrm{T}$ cell responses were minimal or undetectable (Fig. 2B, fig. S6).

We interrogated key indicators of helper responses that support humoral immunity, such as IL-21, a cytokine secreted by follicular helper CD4 T cells (Tfh) that regulate the evolution of memory B cells (29). Five of eight animals dosed twice with $50 \mu \mathrm{g}$ of SpFN had detectable IL-21 responses, as did seven of eight animals given $5 \mu \mathrm{g}$ of the vaccine (Fig. $2 \mathrm{C}$ ). We also examined expression of CD40 ligand (CD40L), a broad $\mathrm{T}$ cell activation marker, expressed on the surfaces of CD4 $\mathrm{T}$ cells that promotes B cell maturation through antibody isotype switching (29). All but one animal receiving two-doses of SpFN had detectable CD40L responses (Fig. 2D), indicating an engaged memory response.

\section{SpFN vaccination reduces viral load after respira- tory SARS-CoV-2 challenge.}

Rhesus macaques generally exhibit mild disease that does not fully recapitulate the severe pneumonia observed in many people with COVID-19 (21). Protective efficacy, therefore, was assessed virologically and pathologically. The primary virologic endpoint was based on the measurement of subgenomic mRNA (sgmRNA) for the envelope (E) gene region of the virus, an indicator of viral replication, in the upper (nasopharyngeal (NP) swabs, saliva) and lower airways (bronchoalveolar lavage (BAL) fluid). sgmRNA concentrations $\left(\log _{10}\right.$ copies $\left./ \mathrm{ml}\right)$ of vaccinated animals were compared to controls. On the second day after simultaneous respiratory mucosal challenge by the intratracheal and intranasal routes, sgmRNA concentrations in the BAL fluid of control animals peaked at a mean of $10^{6}$ copies $/ \mathrm{ml}$ (Fig. 3A). In contrast, none of the eight animals that received two doses of $50 \mu \mathrm{g} \mathrm{SpFN}$ had detectable sgmRNA at day 2. By day 4 sgmRNA was undetectable in the BAL fluid of all animals of the $5 \mu \mathrm{g}$ vaccine group and all but one animal that received single dose SpFN.

Whereas sgmRNA concentrations reached a mean of $10^{7}$ copies/ml in the NP swabs of control animals at day two after challenge, sgmRNA was undetectable in five of eight animals that received two doses of $50 \mu \mathrm{g}$ SpFN (Fig. 3B). All animals in this group had undetectable virus from day four onward, whereas virus persisted in the control animals through day 10. Five of eight controls had high concentrations of sgmRNA in saliva on day two post-challenge, whereas virus was undetectable in all animals of the two-dose $50 \mu \mathrm{g}$ SpFN group (Fig. 3C). Total viral load in the BAL fluid, NP swabs and saliva were similar to those observed for sgmRNA (fig. S7).

SpFN vaccination provides protection from lung pathology after SARS-CoV-2 challenge.

One section of lung tissue from each lung lobe (six sections per animal) was fixed and stained at one-to-two weeks after virus challenge and evaluated under light microscopy and by immunohistochemistry. Unvaccinated control animals developed histopathologic evidence of multifocal, moderate interstitial pneumonia at 7 days after challenge (Fig. 4A). The pneumonia was characterized by type II pneumocyte hyperplasia, alveolar septal thickening, edema and necrotic debris, pulmonary macrophage infiltration and vasculitis of smaller caliber blood vessels. None of the vaccinated animals, however, had evidence of interstitial pneumonia (Fig. 4B to D). Immunohistochemistry revealed viral antigen in alveolar pneumocytes and pulmonary macrophages in at least one lung section of every control animal (Fig. 4E). In contrast, no viral antigen was detected in any of the lung sections taken from vaccinated animals (Fig. $4 \mathrm{~F}$ to $\mathrm{H})$.

SpFN elicits broadly neutralizing antibodies that bind to variants of concern.

We assessed the serum antibody responses elicited by the SpFN vaccine against four circulating SARS-CoV-2 VOCs: B.1.1.7 (alpha variant), B.1.351 (beta variant), P.1 (gamma variant) and B.1.617.2 (delta variant). Serum binding assessment by biolayer interferometry to the first three variant forms of SARS-CoV-2 RBD showed no change in binding to B.1.1.7 (N501Y mutation) or B.1.351 (K417N, E484K, N501Y mutations) in the two-dose $50 \mu \mathrm{g} \mathrm{SpFN}$ group (fig. S8). Serum binding assessment by biolayer interferometry to these same 
variant forms of SARS-CoV-2 RBD showed no change in binding to B.1.1.7 (N501Y mutation), but a 25\% reduction in binding to B.1.351 (K417N, E484K, N501Y mutations) in the twodose $50 \mu \mathrm{g}$ SpFN group (fig. S8). We next assessed the serum neutralizing activity elicited by the SpFN vaccine against all four VOCs, including B.1.617.2 ( $\delta$ variant). Serum samples from all vaccinated NHPs elicited potent neutralizing activity against all variants in two orthogonal virus neutralization assays. Neutralization capacity of the authentic B.1.1.7 virus variant was high across all vaccine groups (Fig. 5A to $\mathrm{C}$ ) and was significantly $(\mathrm{p}=0.02)$ higher than neutralization of wild-type WA-1 in the two-dose $50 \mu \mathrm{g}$ group (Fig. 5A). Neutralizing activity against the authentic B.1.351, P.1 and B.1.617.2 virus variants, however, was diminished slightly (Fig. 5A to C), except in the two-dose $50 \mu \mathrm{g}$ group (Fig. 5A). Neutralizing activity against the B.1.1.7 in an orthogonal pseudovirus assay revealed equivalent $\mathrm{ID}_{50}$ GMTs to the WA-1 wild-type pseudovirus (Fig. $5 \mathrm{D}$ to $\mathrm{F}$ ). Reductions in neutralizing activity against the B.1.351 pseudovirus, however, were slightly more pronounced in the pseudovirus assay as compared to the authentic virus assay. For example, the reciprocal ID $_{50}$ GMT dropped five-fold in the two-dose $50 \mu \mathrm{g}$ group, but remained high at a value 10,209 (Fig. 5D). The absolute neutralizing antibody titers were generally elevated after two doses of vaccine, irrespective of the virus variant against which they were measured (Fig. 5G).

We expanded the assessment of the immunogenicity breadth to the interrogation of neutralizing and non-neutralizing antibody and cellular immune responses against SARSCoV-1. Binding of vaccinee serum samples to SARS-CoV-1 $\mathrm{RBD}$, as measured by biolayer interferometry, was absent in controls but was relatively potent in vaccinated animals, binding at half the strength of that observed to SARS-CoV-2 RBD (Fig. 6A, fig. S3, S4). Antibody-dependent cellular phagocytotic activity also increased in all vaccine groups, reaching a score that was 100-fold higher than baseline or compared to unvaccinated controls when measured two-weeks after last $50 \mu \mathrm{g}$ SpFN vaccination (Fig. 6B). Two vaccinations with high-dose SpFN also yielded plaque reduction neutralizing activity against authentic SARS-CoV-1 with a reciprocal ID $_{50}$ GMT of 390 that was significantly increased above background ( $p=0.01$, Fig. $6 \mathrm{C}$ ). An orthogonal pseudovirus neutralization assay exhibited some background activity in PBS controls. We minimized this background by analyzing neutralization activity at a $90 \%$ inhibitory dilution $\left(\mathrm{ID}_{90}\right)$ and found that two doses of $50 \mu \mathrm{g} \mathrm{SpFN}$ induced a SARS-CoV-1 neutralizing antibody titer that was 6-fold higher (GMT 667) than controls (Fig. 6D). CD4 T cell responses to SARS-CoV-1 spike protein peptides, though lower in absolute percentage than against SARS-CoV-2, were still robust and Th1-biased (Fig. 6E and F). The CD8 $\mathrm{T}$ cell response, in contrast, was minimal (fig. S9). Overall, the immune response elicited by
SpFN against SARS-CoV-1, though lower in magnitude, recapitulated the quality of response against SARS-CoV-2.

\section{DISCUSSION}

The recent success in the rapid development of safe and efficacious SARS-CoV-2 vaccines has been tempered by the emergence of virus variants to which vaccine-induced immunity has shown diminished potency or efficacy (30-33). Thus, there remains a need for next-generation vaccines that target the broadening antigenic diversity of SARS-CoV-2 and related coronaviruses. The major vaccines that have progressed to human efficacy trials and have been granted either approval or emergency use authorization all present the SARS-CoV-2 spike protein that is based on the genetic sequence of the Wuhan-Hu-1 isolate. All of these vaccines have demonstrated protective efficacy in NHPs against respiratory mucosal challenge with the closely matched USA-WA1/2020 $(25,34-38)$. These earlier animal studies, however, did not evaluate the neutralization capacity of serum against other coronavirus species. In the current study we demonstrate that an adjuvanted recombinant nanoparticle vaccine, SpFN, elicited high titers of that antibodies neutralized SARS-CoV2 and rapidly protected against SARS-CoV-2 infection. We also found that, compared to wild type virus, $\mathrm{SpFN}$ elicited serum virus neutralizing activity that was either higher or equivalent against four major VOCs (B.1.1.7, B.1.351, P.1, B.1.617.2) in an authentic virus neutralization assay and equivalent or mildly diminished against two VOCs in a pseudovirus neutralization assay (B.1.1.7, B.1.351). Finally, SpFN induced robust neutralizing activity against SARS-CoV-1, a separate species that has $26 \%$ and $36 \%$ sequence divergence in the spike protein and S1 subunit, respectively (39), which is important for protection in animal models $(40,41)$.

SARS-CoV-2 vaccine efficacy studies in NHPs generally compare elicited antibody responses to those from patients who have recovered from COVID-19. We found neutralizing activity in the two-dose $50 \mu \mathrm{g}$ SpFN group to be ten-fold higher than that in recovering patients. The lack of standardization across convalescent serum panels and absence of head-to-head comparisons of candidate vaccines makes it difficult to compare immunogenicity profiles. Direct comparisons come with a qualification that immunogenicity output assays have been in the process of harmonization. Bearing this caveat in mind, we found that SARS-CoV-2 antibody responses in animals vaccinated with high-dose $\mathrm{SpFN}$ were robust when set in the context of the entire vaccine landscape, to include genetic vaccines $(34,38)$, recombinant virus vector vaccines $(25,37)$, and adjuvanted protein subunit vaccines (35). Although direct quantitative comparisons of NHP vaccine studies can be difficult to interpret, we have made attempts to mitigate differences in assay outputs by analyzing specimens with orthogonal assays harmonized to consensus platforms. Specifically, the pseudovirus neutralization assay 
we developed for our immunogenicity assessments demonstrated equivalence to platforms used for the assessment of other major vaccines through participation in the SARS-CoV2 Neutralizing Assay Concordance Survey 1 coordinated by the External Quality Assurance Program Oversight Laboratory/Virology Quality Assurance Program at the Duke $\mathrm{Hu}$ man Vaccine Institute (42).

Potent neutralizing antibody responses may offer advantages for both vaccine efficacy and durability. Thus far, neutralizing activity has been predictive of efficacy in human trials, as vaccines that generate lower antibody titers have diminished efficacy (43). An open question remains, however, regarding the length of immunity conferred by SARS-CoV-2 vaccines. Among viral infections for which neutralizing antibodies are the primary correlate of protection, peak titers have been shown to be predictive of durability and may serve as one of several indicators of length of vaccine-elicited protective immunity (44-46). As such, SpFN may offer some measure of a durable immune response; though this will require empirical confirmation.

Overall, SpFN vaccination induced serum cross-neutralizing antibody responses. Additionally, we found serum binding to mutated SARS-CoV-2 RBD was either unaffected or mildly reduced. We also found serum binding to mutated SARS-CoV-2 RBD was either unaffected or mildly diminished. Other reports of nanoparticle vaccine approaches presenting RBD also have shown a breadth of neutralizing antibody responses against multiple sarbecoviruses (47-49). Similar to other studies, SpFN vaccination induces comprehensive binding and neutralizing antibody responses and a balanced cellular immune response against SARS-CoV-1. Although background neutralizing activity was high in one assay, neutralizing potency against SARS-CoV-1 was confirmed in an orthogonal virus neutralization assay. Still, we plan to test purified IgG from vaccine serum in both assays to control for the background activity at baseline and in controls.

We hypothesize that the breadth of immune response elicited by the SpFN vaccine may be the result of several factors. First, the quantity of the polyclonal antibody response may surpass a threshold that overcomes resistance to neutralization of antigenically distinct virus variants. Second, repetitive, ordered display of antigen on a self-assembling nanoparticle has been shown to drive an expanded germinal center reaction with resultant increases in B cell receptor mutation, affinity maturation and plasma cell differentiation (57). Lastly, the adjuvant, ALFQ, may drive some of the breadth through CD4 $\mathrm{T}$ cell activation $(50,51)$, especially given the high Th1 response elicited by the co-formulation. ALFQ, as compared to aluminum hydroxide (Alhydrogel), previously has demonstrated superior immunogenicity when administered with SpFN to C57BL/6 and BALB/c mice (20). As NHPs are a more predictive model with respect to adjuvant performance in humans, we are now conducting a follow-on adjuvant comparison study in NHPs to evaluate the impact of ALFQ on immunogenicity potency and breadth. Additionally, as NHPs do not exhibit the same degree of fidelity as Syrian golden hamsters in terms of developing severe COVID19 disease (21), we have also found SpFN to protect against VOCs in challenge experiments in the latter model (52).

The interpretation of the results from this study is limited by several factors. First, we were able evaluate efficacy our vaccine candidate only against challenge with the Wuhan$\mathrm{Hu}-1$ strain of SARS-CoV-2. This is because VOCs were only beginning to emerge and circulate when this study was conceived and initiated. Our assessment of breadth of the immune response was, instead, evaluated by serum neutralizing activity against a panel of SARS-CoV-2 VOCs as well as SARSCoV-1. Second, we cannot define, from the design and outputs of this study, the relative contributions of the immunogen and adjuvant of our vaccine formulation to the potency and breadth of immune response observed. Finally, we have yet to understand the role and repertoire of the humoral and cellular immune responses elicited by this SpFN. We are carrying out follow on studies examine the mechanisms of immunity conferred by our vaccine candidate.

The collective immune response elicited by SpFN translated into a robust and rapid reduction in replicating virus in the upper and lower airways of animals and resultant prevention of pulmonary pathology. It is notable that SpFN protected against a potent viral challenge, as replicating virus concentrations detected in the upper and lower airways of unvaccinated controls reached a mean of $10^{6}$ to $10^{7}$ copies $/ \mathrm{ml}$. Despite this higher challenge, SpFN still protected lower airway viral burden and disease as early as within one day of virus inoculation. The rapid elimination of replicating virus in the upper airways also lends evidence for potential nearsterilizing immunity, which again may have implications for preventing viral transmission. Altogether, these findings support the further development of SpFN, which has now moved to human evaluation in a phase 1 clinical trial (53).

\section{MATERIALS AND METHODS}

Study design. Thirty-two male and female specific-pathogen-free, research-naïve Chinese-origin rhesus macaques (age 3 to 7 years) were distributed-on the basis of age, weight, and sex-into 4 cohorts of 8 animals (table S1). Sample sizes were set based animal availability and prior experience with other nonhuman primate vaccination/challenge studies. Animals were assigned to groups without a specific randomization scheme; however, no outliers were skewed to any one group (table S1). Animals were vaccinated intramuscularly with either 50 or $5 \mu \mathrm{g}$ of SpFN, formulated with ALFQ, or $1 \mathrm{ml}$ of PBS in the anterior proximal quadriceps muscle, on alternating sides with each dose in the series. Immunizations were administered twice, 4 weeks apart, or once, 4 weeks 
prior to challenge. Animals were challenged with virus stock obtained through Biodefense and Emerging Infections Research Resources Repository Resources (BEI Resources), National Institute of Allergy and Infectious Diseases, National Institutes of Health: SARS-Related Coronavirus 2, Isolate USA-WA1/2020, NR-53780 (Lot\# 70038893). Virus was stored at $-80^{\circ} \mathrm{C}$ prior to use, thawed by hand and placed immediately on wet ice. Stock was diluted to $5 \times 10^{5} \mathrm{TCID}_{50}$ per $\mathrm{ml}$ in PBS and vortexed gently for $5 \mathrm{~s}$ prior to inoculation by combined intratracheal $(1 \mathrm{~mL})$ and intranasal routes $(0.5 \mathrm{~mL}$ per nostril).

All procedures were carried out in accordance with institutional, local, state and national guidelines and laws governing animal research included in the Animal Welfare Act. Animal protocols and procedures were reviewed and approved by the Animal Care and Use Committee of both the US Army Medical Research and Development Command (USAMRDC, protocol 11355007.03) Animal Care and Use Review Office as well as the Institutional Animal Care and Use Committee of Bioqual, Inc. (protocol number 20-092), where nonhuman primates were housed for the duration of the study. USAMRDC and Bioqual, Inc. are both accredited by the Association for Assessment and Accreditation of Laboratory Animal Care and are in compliance with the Animal Welfare Act and Public Health Service Policy on Humane Care and Use of Laboratory Animals.

Vaccine and adjuvant design and production. The spike ferritin nanoparticle (SpFN) vaccine immunogen was produced by linking Helicobacter pylori ferritin to the C-terminal region of the pre-fusion stabilized ectodomain (residues 12-1158) of the SARS-CoV-2 spike protein in a genetic fusion. The immunogen was expressed, purified, and characterized as previously described (20). Briefly, SpFN was derived from the Wuhan-Hu-1 strain genome sequence (GenBank MN9089473), synthesized by Genscript Inc, and subcloned into a modified cytomegalovirus promoter (CMVR) expression vector. Expi293F cells (Thermo Fisher Scientific) were transiently transfected with SpFN plasmid DNA using ExpiFectamine 293 transfection reagent (Thermo Fisher Scientific). Cells were grown in polycarbonate baffled shaker flasks at $34^{\circ} \mathrm{C}$ and $8 \% \mathrm{CO}_{2}$ at 120 revolutions per minute (rpm). Cells were harvested 5 days post-transfection by centrifugation at $3,500 \times \mathrm{g}$ for $30 \mathrm{~min}$. Culture supernatants were filtered with a $0.22-\mu \mathrm{m}$ filter and stored at $4{ }^{\circ} \mathrm{C}$ prior to purification using GNA lectin affinity chromatography. Briefly, $25 \mathrm{~mL}$ GNA-lectin resin (VectorLabs) was used to purify SpFN from 1L of expression supernatant. GNA resin was equilibrated with 10 column volumes (CV) of PBS (pH 7.4) followed by supernatant loading twice at $4^{\circ} \mathrm{C}$. Unbound protein was removed by washing with $20 \mathrm{CV}$ of PBS buffer. Bound protein was eluted with $250 \mathrm{mM}$ methyl- $\alpha$-D mannopyranoside in PBS buffer (pH 7.4). SpFN was further purified by size-exclusion chromatography using a 16/60 Superdex200 purification column. Purification purity for all the proteins was assessed by SDS-PAGE. Endotoxin concentrations for SpFN was assessed (Endosafe nexgen-PTS, Charles River Laboratories) and $5 \% \mathrm{v} / \mathrm{v}$ glycerol was added prior to filtersterilization with a $0.22-\mu \mathrm{m}$ filter, flash-freezing in liquid nitrogen and storage at $-80^{\circ} \mathrm{C}$. SpFN antigenicity was assessed by Octet Biolayer Interferometry with a set of antibodies that included CR3022 (20) and SR1-SR5 (potent neutralizing antibodies targeting the ACE2 binding site of the RBD; kindly provided by S. Rajan, P.M. McTamney, and M.T. Esser of Astra Zeneca). Size and consistency of the SpFN immunogen was determined by negative-stain electron microscopy. These measurements ensured lot-to-lot consistency of the SpFN immunogen.

The adjuvant, Army Liposomal Formulation with QS21 (ALFQ), was prepared as previously described (54). Briefly, ALFQ is a unilamellar liposome that contains saturated phospholipids, cholesterol, monophosphoryl lipid A and the saponin, QS-21. It is comprised of dimyristoyl phosphatidylcholine (DMPC), dimyristoyl phosphatidylglycerol (DMPG), cholesterol (Chol), and synthetic monophosphoryl lipid A (3D-PHAD) (Avanti Polar Lipids) and QS-21 (Desert King). DMPC and Chol were dissolved in chloroform and DMPG and 3D-PHAD were dissolved in chloroform:methanol at a ratio of 9:1. The lipids were mixed in a molar ratio of 9:1:12.2:0.114 (DMPC:DMPG:Chol:3D-PHAD) and the solvent was removed by rotary evaporation. 3DPHAD and QS-21 doses were 200 and $100 \mu \mathrm{g}$, respectively. The lipids were suspended in Sorenson's PBS, pH 6.2, microfluidized to form small unilamellar vesicles (SUV) and filtered. QS-21 was solubilized in Sorenson's PBS, pH 6.2, filtered and added to the SUV to form ALFQ. The final lipid ratio was 9:1:12.2:0.114:0.044 (DMPC:DMPG:Chol:3DPHAD:QS-21).

Immunogen was diluted in Dulbecco's PBS (Lot\#723188, Quality Biological) to $0.1 \mathrm{mg} / \mathrm{ml}$ or $0.01 \mathrm{mg} / \mathrm{ml}$ and mixed 1:1 with $2 \mathrm{X}$ ALFQ liposomes on a tilted slow-speed roller at room temperature for $10 \mathrm{~min}$, followed by incubation at $4{ }^{\circ} \mathrm{C}$ for 50 $\mathrm{min}$. All reagents were equilibrated to room temperature before use and immunizations were performed within 4 hours of vaccine formulation. Each vaccine comprised a $1.0 \mathrm{ml}$ solution of SpFN formulated with ALFQ.

Convalescent Plasma Samples. A panel of 41 human convalescent-phase plasma samples were obtained from BEI Resources Repository $(n=30)$, StemExpress $(n=7)$ and a Walter Reed Army Institute of Research institutional review board-approved leukapheresis protocol $(\# 1386 \mathrm{H})(\mathrm{n}=4)$ for which written informed consent was provided by participants. Samples were collected from males $(n=20)$ and females $(\mathrm{n}=21)$ ranging in age from 31 to 71 years. Individuals donated plasma specimens approximately four-to-eight weeks after 
laboratory-confirmed SARS-CoV-2 infection and had histories of asymptomatic-to-mild-to-moderate clinical presentation.

Binding antibody measurements. SARS-CoV-2-specific binding IgG antibody responses were measured using MULTI-SPOT 96-well plates from Meso Scale Discovery (MSD). Multiplex wells were coated with spike (S), RBD and nucleocapsid $(\mathrm{N})$ antigens at a concentration of 200-400 $\mathrm{ng} / \mathrm{ml}$ and bovine serum antigen, which served as a negative control. Four-plex MULTISPOT plates were blocked with MSD Blocker A buffer for 1 hour at room temperature, shaking at $700 \mathrm{rpm}$. Plates were washed with buffer before the addition of reference standard and calibrator controls. Serum samples were diluted at 1:1,000 to 1:100,000 in diluent 100 buffer (provided with manufacturer kit), then added to each of four wells. Plates were incubated with shaking at $700 \mathrm{rpm}$ for two hours at room temperature and then washed. MSD SULFO-TAG anti-IgG antibody was added to each well. Plates were incubated for 1 hour at room temperature with shaking at $700 \mathrm{rpm}$ and washed, then MSD GOLD Read buffer B was added to each well. Plates were read by the MESO SECTOR SQ 120 Reader. IgG concentration was calculated using DISCOVERY WORKBENCH MSD Software and reported as arbitrary units $(\mathrm{AU}) / \mathrm{ml}$.

The ability of SARS-CoV-2 spike-specific binding antibodies to inhibit spike protein or RBD binding to the ACE2 receptor was also measured using MULTI-SPOT 96-well plates (MSD). Antigen-coated plates were blocked and washed as described above. Assay calibrator and samples were diluted at 1:25 to 1:1,000 in MSD Diluent buffer, then added to the wells. Plates were incubated for 1 hour at room temperature, shaking at $700 \mathrm{rpm}$. ACE2 protein conjugated with MSD SULFO-TAG was added and plates were incubated for 1 hour at room temperature, shaking at 700rpm. Plates were washed and read as described above. $\mathrm{AU} / \mathrm{ml}$ concentration of inhibitory antibodies was calculated with DISCOVERY WORKBENCH MSD Software.

Binding antibody measurements by octet biolayer interferometry were made on biosensors of the Octet FortéBio Red96 instrument (Sartorius) that were hydrated in PBS prior to use. All assay steps were performed at $30^{\circ} \mathrm{C}$ with agitation set at $1,000 \mathrm{rpm}$. Baseline equilibration of the antiHis-tag biosensors (HIS1K biosensors with a conjugated Penta-His antibody (Sartorius) was carried out with PBS for $15 \mathrm{~s}$, prior to SARS-CoV2-RBD (30 $\mu \mathrm{g} / \mathrm{ml}$ diluted in PBS) loading for $120 \mathrm{~s}$. After dipping in assay buffer (15 s in PBS), biosensors were dipped in the serum samples (100-fold dilution) for $180 \mathrm{~s}$. Binding response $(\mathrm{nm})$ at $180 \mathrm{~s}$ was recorded for each sample.

SARS-CoV-1 and SARS-CoV-2 Pseudovirus Neutralization. The spike protein expression plasmid sequence for SARS-CoV-2 was codon optimized and modified to remove an
18 amino acid endoplasmic reticulum retention signal in the cytoplasmic tail to improve spike protein incorporation into pseudovirions (PSV) and thereby enhance infectivity. SARSCoV-2 PSV were produced by co-transfection of HEK293T/17 cells with a SARS-CoV-2 spike protein-expressing plasmid (pcDNA3.4), derived from the Wuhan-Hu-1 genome sequence (GenBank accession number: MN908947.3) and an HIV-1 (pNL4-3.Luc.R-E-, NIH HIV Reagent Program, Catalog number 3418). Infectivity and neutralization titers were determined using ACE2-expressing HEK293 target cells (Integral Molecular) in a semi-automated assay format using robotic liquid handling (Biomek NXp Beckman Coulter). Virions pseudotyped with the vesicular stomatitis virus (VSV) G protein were used as a non-specific control. Serum samples were diluted 1:40 in growth medium (10\% fetal bovine serum, $2.5 \%$ HEPES, $0.5 \%$ Gentamicin, 0.1\% Puromycin in Dulbecco's Modified Eagle Medium); then $25 \mu \mathrm{l} /$ well was added, in triplicate, to a white 96 -well plate. An equal volume of diluted SARS-CoV-2 PSV was added to each well and plates were incubated for 1 hour at $37^{\circ} \mathrm{C}$. Target cells were added to each well (40,000 cells/ well) and plates were incubated for an additional 48 hours. Relative light units (RLU) were measured with the EnVision Multimode Plate Reader (Perkin Elmer) using the Bright-Glo Luciferase Assay System (Promega). Neutralization dose-response curves were fitted by nonlinear regression using the LabKey Server, as previously described (55). Final titers are reported as the reciprocal of the dilution of serum necessary to achieve $50 \%\left(\mathrm{ID}_{50}\right)$ and $90 \%$ neutralization $\left(\mathrm{ID}_{90}\right.$ ). Assay equivalency was established by participation in the SARS-CoV-2 Neutralizing Assay Concordance Survey (SNACS) run by the Virology Quality Assurance Program and External Quality Assurance Program Oversite Laboratory (EQAPOL) at the Duke Human Vaccine Institute, sponsored through programs supported by the National Institute of Allergy and Infectious Diseases, Division of AIDS.

Authentic SARS-CoV-2 wild-type neutralization assay. Authentic virus neutralization was measured using SARS-CoV-2 (2019-nCoV/USA_WA1/2020) that was obtained from the Centers for Disease Control and Prevention and passaged once in Vero CCL81 cells (American Type Culture Collection (ATCC)). Rhesus serum samples were serially diluted and incubated with 100 focus-forming units (FFU) of SARSCoV-2 for 1 hour at $37^{\circ} \mathrm{C}$. Serum-virus mixtures were added to Vero E6 cells in 96-well plates and incubated for 1 hour at $37^{\circ} \mathrm{C}$. Cells were overlaid with $1 \%(\mathrm{w} / \mathrm{v})$ methylcellulose in Minimal Essential Media (Sigma-Aldrich). After 30 hours, cells were fixed with $4 \%$ paraformaldehyde in PBS for 20 min at room temperature then washed and stained overnight at $4^{\circ} \mathrm{C}$ with $1 \mu \mathrm{g} / \mathrm{ml}$ of antibody CR3022 in PBS supplemented with $0.1 \%$ saponin and $0.1 \%$ bovine serum albumin. Cells were subsequently stained with horseradish peroxidase (HRP)-conjugated goat anti-human IgG for 2 hours at room 
temperature. SARS-CoV-2-infected cell foci were visualized with TrueBlue peroxidase substrate (KPL) and quantified using ImmunoSpot microanalyzer (Cellular Technologies). Neutralization curves were generated with Prism software (GraphPad Prism 8.0).

Authentic SARS-CoV-2 variant and SARS-CoV-1 neutralization assay. The SARS-CoV-2 viruses USAWA1/2020 (WA1), USA/CA_CDC_5574/2020 (B1.1.7), hCoV19/South Africa/KRISP-EC-K005321/2020 (B.1.351), hCoV19/Japan/TY7-503/2021, hCoV-19/USA/PHC658/2021 (B.1.617.2) were obtained from BEI Resources (NIAID, NIH) and propagated for one passage using Vero clone E6 cells. Virus infectious titer was determined by an end-point dilution and cytopathic effect (CPE) assay on Vero-E6 cells as described previously $(56,57)$. An end-point dilution microplate neutralization assay was performed to measure the neutralization activity of NHP serum samples. In brief, serum samples were heat inactivated and subjected to successive threefold dilutions starting from 1:50. Triplicates of each dilution were incubated with SARS-CoV-2 at a multiplicity of infection (MOI) of 0.1 in Eagle's Minimal Essential Medium (EMEM) with $7.5 \%$ inactivated fetal calf serum (FCS) for 1 hour at $37^{\circ} \mathrm{C}$. Post incubation, the virus-antibody mixture was transferred onto a monolayer of Vero-E6 cells grown overnight. The cells were incubated with the mixture for about 70 hours. CPE of viral infection was visually scored for each well in a blinded fashion by two independent observers. The results were then reported as percentage of neutralization at a given sample dilution. A SARS-CoV-1 authentic plaque reduction virus neutralization assay was performed similarly to previously described (58), with the following modifications. The starting dilution of serum was 1:5 and about 100 plaque-forming units of virus were used for virus and serum incubation. The overlay used after virus adsorption was Dulbecco's Modified Eagle Medium (Gibco) containing 2\% $\quad$ FBS and 20\% methylcellulose. Plates were then incubated for 5 days, and post crystal violet staining the washing step utilized water. Plaques were graded as follows: approximately 25 plaques/25\% monolayer damage (MD; -/+); approximately 50 plaques/50\% MD) (+); approximately 75 plaques/75\% MD $(++)$; approximately 100 plaques/100\% MD (+++). All negative control wells were solid monolayers.

Antibody-Dependent Neutrophil Phagocytosis (ADNP). Biotinylated SARS-CoV-2 prefusion stabilized S trimer was incubated with yellow-green streptavidin-fluorescent beads (Molecular Probes) for 2 hours at $37^{\circ} \mathrm{C}$. Ten $\mu l$ of a 100 -fold dilution of beads and protein was incubated for 2 hours at $37^{\circ} \mathrm{C}$ with $100 \mu \mathrm{l}$ of 8,100 -fold diluted plasma samples before addition of effector cells (50,000 cells/well). Fresh human peripheral blood mononuclear cells were used as effector cells after red blood cell lysis with ACK lysing buffer (Thermo Fisher Scientific). After 1 hour, incubation at $37^{\circ} \mathrm{C}$, the cells were washed, surface stained, fixed with $4 \%$ formaldehyde solution (Tousimis) and fluorescence was evaluated on an LSRII flow cytometer (BD Biosciences). Antibodies used for flow cytometry included anti-human CD3 Alexa Fluor 700 (clone UCHT1) and anti-human CD14 Allophycocyanin Cynanine Dye 7 (APC-Cy7) (clone M $\phi$ P9) from BD Biosciences, as well as anti-human CD66b Pacific Blue (clone G10F5) from BioLegend. A phagocytic score was calculated by multiplying the percentage of bead-positive neutrophils (side scatter high, CD3-CD14-CD66 ${ }^{+}$) by the geometric mean of the fluorescence intensity of bead-positive cells; and dividing by 10,000 .

Antibody-Dependent Cellular Phagocytosis (ADCP). ADCP was measured as previously described. Briefly, biotinylated SARS-CoV-1 or SARS-CoV-2 prefusion-stabilized spike protein trimer was incubated with red streptavidin-fluorescent beads (Molecular Probes) for 2 hour at $37^{\circ} \mathrm{C}$. Ten $\mu \mathrm{l}$ of a 100-fold dilution of beads-protein was incubated for 2 hours at $37^{\circ} \mathrm{C}$ with $100 \mu$ l of 8,100 -fold (SARS-CoV-2) or 900fold (SARS-CoV-1) diluted plasma samples before addition of THP-1 cells (20,000 cells per well; Millipore Sigma). After a 19 hour incubation at $37^{\circ} \mathrm{C}$, the cells were fixed with $2 \%$ formaldehyde solution (Tousimis) and fluorescence was evaluated on an LSRII flow cytometer (BD Biosciences). The phagocytic score was calculated by multiplying the percentage of bead-positive cells by the geometric mean of the fluorescence intensity of bead-positive cells, and dividing by 10,000.

Antibody-Dependent Complement Deposition (ADCD). SARS-CoV-2 spike protein-expressing expi293F cells were generated by transfection with linearized plasmid (pcDNA3.1) encoding codon-optimized full-length SARS-CoV2 spike protein matching the amino acid sequence of the ILCDC-IL1/2020 isolate (GenBank ACC\# MN988713). Stable transfectants were single-cell sorted and selected to obtain a high spike surface-expressing clone (293F-spike-S2A). ADCD was adapted from methods previously described (59). Briefly, SARS-CoV-2 spike protein-expressing expi293F cells were incubated with 10 -fold diluted, heat-inactivated $\left(56^{\circ} \mathrm{C}\right.$ for 30 min) plasma samples for $30 \mathrm{~min}$ at $37^{\circ} \mathrm{C}$. Cells were washed twice and resuspended in R10 media. During this time, lyophilized guinea pig complement (CL4051, Cedarlane) was reconstituted in $1 \mathrm{ml}$ cold water and centrifuged for $5 \mathrm{~min}$ at $4^{\circ} \mathrm{C}$ to remove aggregates. Cells were washed with PBS and resuspended in $200 \mu$ l of guinea pig complement, which was prepared at a 1:50 dilution in Gelatin Veronal Buffer with $\mathrm{Ca}^{2+}$ and $\mathrm{Mg}^{2+}$ (IBB-300x, Boston BioProducts). After incubation at $37^{\circ} \mathrm{C}$ for $20 \mathrm{~min}$, cells were washed in PBS $15 \mathrm{mM}$ EDTA (Thermo Fisher Scientific) and stained with an anti-Guinea Pig Complement C3 FITC (polyclonal, Thermo Fisher Scientific). Cells were then fixed with $4 \%$ formaldehyde solution and fluorescence was evaluated on a LSRII flow cytometer 
(BD Biosciences).

Opsonization. SARS-CoV-2 spike protein-expressing expi293F cells were generated by transfection with linearized plasmid (pcDNA3.1) encoding codon-optimized full-length SARS-CoV-2 spike protein matching the amino acid sequence of the IL-CDC-IL1/2020 isolate (GenBank ACC\# MN988713). Stable transfectants were single-cell sorted and selected to obtain a high Spike surface-expressing clone (293F-SpikeS2A). SARS-CoV-2 spike protein-expressing cells were incubated with 200 -fold diluted plasma samples for $30 \mathrm{~min}$ at $37^{\circ} \mathrm{C}$. Cells were washed twice and stained with anti-human IgG phycoerythrin (PE), anti-human IgM Alexa Fluor 647, and anti-human IgA FITC (Southern Biotech). Cells were then fixed with $4 \%$ formaldehyde solution and fluorescence was evaluated on an LSRII flow cytometer (BD Biosciences).

Trogocytosis. Trogocytosis was measured using a previously described assay (27). Briefly, SARS-CoV-2 spike expressing expi293F cells were stained with PKH26 (Sigma-Aldrich). Cells were then washed with and resuspended in R10 media. Cells were then incubated with 200-fold diluted plasma samples for $30 \mathrm{~min}$ at $37^{\circ} \mathrm{C}$. Effector peripheral blood mononuclear cells were next added to the R10 media at an effector to target (E:T) cell ratio of 50:1 and then incubated for 5 hours at $37^{\circ} \mathrm{C}$. After the incubation, cells were washed, stained with live/dead aqua fixable cell stain (Life Technologies) and CD14 APC-Cy7 (clone $\mathrm{M} \phi \mathrm{P} 9$ ) for $15 \mathrm{~min}$ at room temperature, washed again, and fixed with $4 \%$ formaldehyde (Tousimis) for $15 \mathrm{~min}$ at room temperature. Fluorescence was evaluated on a LSRII flow cytometer (BD Biosciences). Trogocytosis was evaluated by measuring the PKH26 mean fluorescence intensity of the live CD14 ${ }^{+}$cells.

Intracellular Cytokine Staining. Cryopreserved peripheral blood mononuclear cells were thawed and rested for 6 hours in R10 with $50 \mathrm{U} / \mathrm{mL}$ Benzonase Nuclease (Sigma Aldrich). They were then stimulated for 12 hours with two pools of peptides spanning the spike protein of either SARS-CoV-2 or SARS-CoV-1 $(1 \mu \mathrm{g} / \mathrm{mL}$, JPT, PM-WCPV-S and PM-CVHSA$\mathrm{S}$ respectively) in the presence of Brefeldin A $(0.65 \mu \mathrm{L} / \mathrm{mL}$, GolgiPlug, BD Biosciences Cytofix/Cytoperm Kit, Cat. 555028), co-stimulatory antibodies anti-CD28 (BD Biosciences Cat. $5557251 \mu \mathrm{g} / \mathrm{mL}$ ) and anti-CD49d (BD Biosciences Cat. 555501; $1 \mu \mathrm{g} / \mathrm{mL}$ ), and CD107a (H4A3, BD Biosciences Cat. 561348, Lot 9143920 and 253441). Following stimulation, cells were stained serially with LIVE/DEAD Fixable Blue Dead Cell Stain in PBS for $20 \mathrm{~min}$ at room temperature (Thermo Fisher Scientific \#L23105) and a cocktail of fluorescently-labeled antibodies (BD Biosciences unless otherwise indicated) to cell surface markers CD4-PE-Cy5.5 (S3.5, Thermo Fisher \#MHCD0418, Lot 2118390, 1:80), CD8 BV570 (RPA-T8, BioLegend \#301038, Lot B281322, 1:160), CD45RA BUV395 (5H9, \#552888, Lot 154382 and 259854, 1:160), CD28 BUV737 (CD28.2, \#612815, Lot 0113886, 1:20), CCR7 BV650
(GO43H7, \# 353234, Lot B297645, 1:20) and HLA-DR BV480 (G46-6, \# 566113, Lot 0055314, 1:640) in 4\% fetal bovine serum in PBS for $20 \mathrm{~min}$ at room temperature. Intracellular cytokine staining was performed following fixation and permeabilization per manufacturer's instructions (BD $\mathrm{Cy}$ tofix/Cytoperm, BD Biosciences) with CD3 APC-Cy7 (SP34-2, \#557757, Lot 6140803, 1:1,282), CD154 PE-Cy7 (24-31, BioLegend \# 310842, Lot B264810 and B313191, 1:40), IFN-Y Alexa Fluor 700 (B27, \# 506516, Lot B187646 and B290145, 1:1,282), TNF- $\alpha$ FITC (MAb11, \# 554512, Lot 15360, 1:160), IL2 BV750 (MQ1-17H12, BioLegend \#566361, Lot 0042313, 1:160), IL-4 BB700 (MP4-25D2, Lot 0133487 and 0308726, 1:320), MIP-1b PE (D21-1351, \# 550078, Lot 9298609, 1:160), CD69 Electron coupled dye (ECD, phycoerythrin-Texas Red conjugate) (TP1.55.3, Beckman Coulter Life Sciences \# 6607110, Lot 7620070 and 7620076, 1:80), IL-21 Alexa Fluor 647 (3A3-N2.1, \# 560493, Lot 9199272, 1:20), IL-13 BV421 (JES10-5A2, \# 563580, Lot 9322765, 210147 and 169570, 1:20) and IL-17A BV605 (BL168, BioLegend \#512326, B289357, 1:20). Sample staining was measured on a FACSymphony A5 SORP (Becton Dickenson) and data analyzed using FlowJo v.9.9 software (Tree Star, Inc.). The gating strategy is shown in fig. S10. CD4 and CD8 T cell subsets were pre-gated on memory markers prior to assessing cytokine expression as follows: single-positive or double-negative for CD45RA and CD28. Boolean combinations of cells expressing one or more cytokines were used to assess the total spike protein-specific response of memory CD4 or CD8 T cells. Responses from the two-peptide pools spanning SARS-CoV-2 spike protein or SARS-CoV-1 were summed. Display of multicomponent distributions were performed with SPICE v6.0 (NIH).

Total and Sub-Genomic Messenger (sgm) RNA Quantification. Real time quantitative polymerase chain reaction (RT-qPCR) was carried out for subgenomic messenger RNA (sgmRNA) and viral load RNA quantification from NP swab, BAL fluid and saliva samples. Primers targeted the envelope (E) gene of SARS-CoV-2 (table S2). RNA was extracted from $200 \mu \mathrm{l}$ of NP swab media or BAL specimens using the EZ1 DSP Virus kit (Qiagen) on the EZ1 Advanced XL instrument (Qiagen). Briefly, samples were lysed in $200 \mu \mathrm{l}$ of ATL buffer (Qiagen) and transferred to the Qiagen EZ1 for extraction. Bacteriophage MS2 (ATCC) was added to the RNA carrier and used as an extraction control to monitor efficiency of RNA extraction and amplification (60). Purified RNA was eluted in $90 \mu$ l elution buffer (AVE). The RT-qPCR amplification reactions were performed in separate wells of a 96-well Fast plate for the 3 targets: sgmRNA, RNA viral load, and MS2 RNA using $10 \mu \mathrm{l}$ of extracted material $0.72 \mathrm{uM}$ of primer and 0.2uM of probe and 1x TaqPath 1-Step RT-qPCR (A15299: Life Technologies, Thermo Fisher Scientific). Amplification cycling conditions were: $2 \mathrm{~min}$ at $25^{\circ} \mathrm{C}, 15 \mathrm{~min}$ at $50^{\circ} \mathrm{C}, 2 \mathrm{~min}$ at $95^{\circ} \mathrm{C}$ and 45 cycles of $3 \mathrm{~s}$ at $94^{\circ} \mathrm{C}$ and $30 \mathrm{~s}$ at $55^{\circ} \mathrm{C}$ with 
fluorescence read at $55^{\circ} \mathrm{C}$. An RNA transcript for the SARSCoV-2 E gene was used as a calibration standard. RNA copy values were extrapolated from the standard curve and multiplied by 45 to obtain RNA copies/ml. A negative control (PBS) and two positive controls (heat inactivated SARS-CoV-2, ATCC, VR-1986HK at $10^{6}$ and $10^{3}$ copies $/ \mathrm{ml}$ ), were extracted and used to assess performance of both assays.

Histopathology. Formalin fixed sections of lung tissue were evaluated by light microscopy and immunohistochemistry. Lungs were perfused with $10 \%$ neutral-buffered formalin. Lung sections were processed routinely into paraffin wax, then sectioned at $5 \mu \mathrm{m}$, and resulting slides were stained with hematoxylin and eosin. Immunohistochemistry (IHC) was performed using the Dako Envision system (Dako Agilent Pathology Solutions). Briefly, after deparaffinization, peroxidase blocking, and antigen retrieval, sections were covered with a mouse monoclonal anti-SARS-CoV nucleocapsid protein antibody (\#40143-MM05, Sino Biological) at a dilution of 1:4000 and incubated at room temperature for forty-five minutes. They were rinsed, and the peroxidase-labeled polymer (secondary antibody) was applied for thirty minutes. Slides were rinsed and a brown chromogenic substrate $3,3^{\prime}$ Diaminobenzidine (DAB) solution (Dako Agilent Pathology Solutions) was applied for eight minutes. The substrate-chromogen solution was rinsed off the slides, and slides were counterstained with hematoxylin and rinsed. The sections were dehydrated, cleared with Xyless, and then cover slipped. Tissue section slides were evaluated by a board-certified veterinary anatomic pathologist who was blinded to study group allocations.

Statistical analysis. Raw, individual level data can be found in data file S1. Primary immunogenicity outputs of binding and neutralizing antibody titers as well as $\mathrm{T}$ cell responses were compared across vaccination groups using Kruskal-Wallis test. Non-parametric pairwise comparisons between groups were made using the post-hoc Dunn's test. The same hierarchical analysis was applied to comparisons of sgmRNA concentrations in the NP swabs and BAL fluids of vaccinated versus control groups. Statistical significance was preset at an alpha level of 0.05 . The correlation between dependent $T$ cell responses was assessed by non-parametric Spearman correlation ( $\mathrm{r}$ ).

\section{SUPPLEMENTARY MATERIALS}

www.science.org/doi/10.1126/scitranslmed.abi5735

Figs. S1 to S10

Tables S1 and S2

Data file S1

\section{REFERENCES AND NOTES}

1. M. S. Freedman, K. Ault, H. Bernstein, Advisory Committee on Immunization Practices Recommended Immunization Schedule for Adults Aged 19 Years or Older - United States, 2021. MMWR Morb. Mortal. Wkly. Rep. 70, 193-196 (2021). doi:10.15585/mmwr.mm7006a2 Medline

2. J. R. Mascola, B. S. Graham, A. S. Fauci, SARS-CoV-2 Viral Variants-Tackling a
Moving Target. JAMA 325, 1261-1262 (2021). doi:10.1001/iama.2021.2088 Medline

3. D. Ho et al., Increased Resistance of SARS-CoV-2 Variants B.1.351 and B.1.1.7 to Antibody Neutralization. Res Sq, (2021).

4. J. R. Ortiz, J. Robertson, J.-S. Hsu, S. L. Yu, A. J. Driscoll, S. R. Williams, W. H. Chen, M. C. Fitzpatrick, S. Sow, R. J. Biellik, K. M. Neuzil, The potential effects of deploying SARS-Cov-2 vaccines on cold storage capacity and immunization workload in countries of the WHO African Region. Vaccine 39, 2165-2176 (2021). doi:10.1016/i.vaccine.2021.02.037 Medline

5. H. G. Kelly, H.-X. Tan, J. A. Juno, R. Esterbauer, Y. Ju, W. Jiang, V. C. Wimmer, B. C. Duckworth, J. R. Groom, F. Caruso, M. Kanekiyo, S. J. Kent, A. K. Wheatley, Selfassembling influenza nanoparticle vaccines drive extended germinal center activity and memory B cell maturation. JCl Insight 5, e136653 (2020). doi:10.1172/jci.insight.136653 Medline

6. Y. Kato, R. K. Abbott, B. L. Freeman, S. Haupt, B. Groschel, M. Silva, S. Menis, D. J. Irvine, W. R. Schief, S. Crotty, Multifaceted Effects of Antigen Valency on B Cell Response Composition and Differentiation In Vivo. Immunity 53, 548-563.e8 (2020). doi:10.1016/i.immuni.2020.08.001 Medline

7. R. Übelhart, E. Hug, M. P. Bach, T. Wossning, M. Dühren-von Minden, A. H. C. Horn, D. Tsiantoulas, K. Kometani, T. Kurosaki, C. J. Binder, H. Sticht, L. Nitschke, M. Reth, H. Jumaa, Responsiveness of $B$ cells is regulated by the hinge region of IgD. Nat. Immunol. 16, 534-543 (2015). doi:10.1038/ni.3141 Medline

8. J. M. Bradley, N. E. Le Brun, G. R. Moore, Ferritins: Furnishing proteins with iron. Eur. J. Biochem. 21, 13-28 (2016). doi:10.1007/s00775-016-1336-0 Medline

9. H. D. Kamp, K. A. Swanson, R. R. Wei, P. K. Dhal, R. Dharanipragada, A. Kern, B. Sharma, R. Sima, O. Hajdusek, L. T. Hu, C.-J. Wei, G. J. Nabel, Design of a broadly reactive Lyme disease vaccine. NPJ Vaccines 5, 33 (2020). doi:10.1038/s41541020-0183-8 Medline

10. K. A. Swanson, J. N. Rainho-Tomko, Z. P. Williams, L. Lanza, M. Peredelchuk, M. Kishko, V. Pavot, J. Alamares-Sapuay, H. Adhikarla, S. Gupta, S. Chivukula, S. Gallichan, L. Zhang, N. Jackson, H. Yoon, D. Edwards, C.-J. Wei, G. J. Nabel, A respiratory syncytial virus (RSV) $F$ protein nanoparticle vaccine focuses antibody responses to a conserved neutralization domain. Sci. Immunol. 5, eaba6466 (2020). doi:10.1126/sciimmunol.aba6466 Medline

11. M. Kanekiyo, W. Bu, M. G. Joyce, G. Meng, J. R. R. Whittle, U. Baxa, T. Yamamoto, S. Narpala, J.-P. Todd, S. S. Rao, A. B. McDermott, R. A. Koup, M. G. Rossmann, J. R. Mascola, B. S. Graham, J. I. Cohen, G. J. Nabel, Rational Design of an EpsteinBarr Virus Vaccine Targeting the Receptor-Binding Site. Cell 162, 1090-1100 (2015). doi:10.1016/i.cell.2015.07.043 Medline

12. M. Kanekiyo, C.-J. Wei, H. M. Yassine, P. M. McTamney, J. C. Boyington, J. R. R. Whittle, S. S. Rao, W.-P. Kong, L. Wang, G. J. Nabel, Self-assembling influenza nanoparticle vaccines elicit broadly neutralizing H1N1 antibodies. Nature 499, 102-106 (2013). doi:10.1038/nature12202 Medline

13. H. M. Yassine, J. C. Boyington, P. M. McTamney, C.-J. Wei, M. Kanekiyo, W.-P. Kong, J. R. Gallagher, L. Wang, Y. Zhang, M. G. Joyce, D. Lingwood, S. M. Moin, H. Andersen, Y. Okuno, S. S. Rao, A. K. Harris, P. D. Kwong, J. R. Mascola, G. J. Nabel, B. S. Graham, Hemagglutinin-stem nanoparticles generate heterosubtypic influenza protection. Nat. Med. 21, 1065-1070 (2015). doi:10.1038/nm.3927 Medline

14. https:/clinicaltrials.gov/ct2/show/NCT03186781. (2021).

15. https://clinicaltrials.gov/ct2/show/NCT03814720. (2021)

16. D. Wrapp, N. Wang, K. S. Corbett, J. A. Goldsmith, C.-L. Hsieh, O. Abiona, B. S. Graham, J. S. McLellan, Cryo-EM structure of the 2019-nCoV spike in the prefusion conformation. Science 367, 1260-1263 (2020). doi:10.1126/science.abb2507 Medline

17. G. Dagotto, J. Yu, D. H. Barouch, Approaches and Challenges in SARS-CoV-2 Vaccine Development. Cell Host Microbe 28, 364-370 (2020). doi:10.1016/i.chom.2020.08.002 Medline

18. T. F. Rogers, F. Zhao, D. Huang, N. Beutler, A. Burns, W. T. He, O. Limbo, C. Smith, G. Song, J. Woehl, L. Yang, R. K. Abbott, S. Callaghan, E. Garcia, J. Hurtado, M. Parren, L. Peng, S. Ramirez, J. Ricketts, M. J. Ricciardi, S. A. Rawlings, N. C. Wu, M. Yuan, D. M. Smith, D. Nemazee, J. R. Teijaro, J. E. Voss, I. A. Wilson, R. Andrabi, B. Briney, E. Landais, D. Sok, J. G. Jardine, D. R. Burton, Isolation of potent SARSCoV-2 neutralizing antibodies and protection from disease in a small animal model. Science 369, 956-963 (2020). doi:10.1126/science.abc7520 Medline 
19. T. Zohar, G. Alter, Dissecting antibody-mediated protection against SARS-CoV-2. Nat. Rev. Immunol. 20, 392-394 (2020). doi:10.1038/s41577-020-0359-5 Medline

20. M. G. Joyce et al., SARS-CoV-2 ferritin nanoparticle vaccines elicit broad SARS coronavirus immunogenicity. bioRxiv, (2021).

21. C. Muñoz-Fontela, W. E. Dowling, S. G. P. Funnell, P.-S. Gsell, A. X. Riveros-Balta, R. A. Albrecht, H. Andersen, R. S. Baric, M. W. Carroll, M. Cavaleri, C. Qin, I. Crozier, K. Dallmeier, L. de Waal, E. de Wit, L. Delang, E. Dohm, W. P. Duprex, D. Falzarano, C. L. Finch, M. B. Frieman, B. S. Graham, L. E. Gralinski, K. Guilfoyle, B. L. Haagmans, G. A. Hamilton, A. L. Hartman, S. Herfst, S. J. F. Kaptein, W. B. Klimstra, I. Knezevic, P. R. Krause, J. H. Kuhn, R. Le Grand, M. G. Lewis, W.-C. Liu, P. Maisonnasse, A. K. McElroy, V. Munster, N. Oreshkova, A. L. Rasmussen, J. RochaPereira, B. Rockx, E. Rodríguez, T. F. Rogers, F. J. Salguero, M. Schotsaert, K. J. Stittelaar, H. J. Thibaut, C.-T. Tseng, J. Vergara-Alert, M. Beer, T. Brasel, J. F. W. Chan, A. García-Sastre, J. Neyts, S. Perlman, D. S. Reed, J. A. Richt, C. J. Roy, J. Segalés, S. S. Vasan, A. M. Henao-Restrepo, D. H. Barouch, Animal models for COVID-19. Nature 586, 509-515 (2020). doi:10.1038/s41586-020-2787-6 Medline

22. Z. Beck, G. R. Matyas, R. Jalah, M. Rao, V. R. Polonis, C. R. Alving, Differential immune responses to HIV-1 envelope protein induced by liposomal adjuvant formulations containing monophosphoryl lipid A with or without QS21. Vaccine 33 5578-5587 (2015). doi:10.1016/i.vaccine.2015.09.001 Medline

23. Z. Beck, G. R. Matyas, C. R. Alving, Detection of liposomal cholesterol and monophosphoryl lipid A by QS-21 saponin and Limulus polyphemus amebocyte lysate. Biochim. Biophys. Acta 1848, 775-780 (2015). doi:10.1016/j,bbamem.2014.12.005 Medline

24. N. Suryadevara, S. Shrihari, P. Gilchuk, L. A. VanBlargan, E. Binshtein, S. J. Zost, R. S. Nargi, R. E. Sutton, E. S. Winkler, E. C. Chen, M. E. Fouch, E. Davidson, B. J. Doranz, R. E. Chen, P.-Y. Shi, R. H. Carnahan, L. B. Thackray, M. S. Diamond, J. E. Crowe Jr., Neutralizing and protective human monoclonal antibodies recognizing the N-terminal domain of the SARS-CoV-2 spike protein. Cell 184, 2316-2331.e15 (2021). doi:10.1016/i.cell.2021.03.029 Medline

25. N. B. Mercado, R. Zahn, F. Wegmann, C. Loos, A. Chandrashekar, J. Yu, J. Liu, L. Peter, K. McMahan, L. H. Tostanoski, X. He, D. R. Martinez, L. Rutten, R. Bos, D. van Manen, J. Vellinga, J. Custers, J. P. Langedijk, T. Kwaks, M. J. G. Bakkers, D. Zuijdgeest, S. K. Rosendahl Huber, C. Atyeo, S. Fischinger, J. S. Burke, J. Feldman, B. M. Hauser, T. M. Caradonna, E. A. Bondzie, G. Dagotto, M. S. Gebre, E. Hoffman, C. Jacob-Dolan, M. Kirilova, Z. Li, Z. Lin, S. H. Mahrokhian, L. F. Maxfield, F. Nampanya, R. Nityanandam, J. P. Nkolola, S. Patel, J. D. Ventura, K. Verrington, H. Wan, L. Pessaint, A. Van Ry, K. Blade, A. Strasbaugh, M. Cabus, R. Brown, A. Cook, S. Zouantchangadou, E. Teow, H. Andersen, M. G. Lewis, Y. Cai, B. Chen, A. G. Schmidt, R. K. Reeves, R. S. Baric, D. A. Lauffenburger, G. Alter, P. Stoffels, M. Mammen, J. Van Hoof, H. Schuitemaker, D. H. Barouch, Single-shot Ad26 vaccine protects against SARS-CoV-2 in rhesus macaques. Nature 586, 583-588 (2020). doi:10.1038/s41586-020-2607-z Medline

26. J. Yu, L. H. Tostanoski, L. Peter, N. B. Mercado, K. McMahan, S. H. Mahrokhian, J. P. Nkolola, J. Liu, Z. Li, A. Chandrashekar, D. R. Martinez, C. Loos, C. Atyeo, S. Fischinger, J. S. Burke, M. D. Slein, Y. Chen, A. Zuiani, F. J. N. Lelis, M. Travers, S. Habibi, L. Pessaint, A. Van Ry, K. Blade, R. Brown, A. Cook, B. Finneyfrock, A. Dodson, E. Teow, J. Velasco, R. Zahn, F. Wegmann, E. A. Bondzie, G. Dagotto, M. S. Gebre, X. He, C. Jacob-Dolan, M. Kirilova, N. Kordana, Z. Lin, L. F. Maxfield, F. Nampanya, R. Nityanandam, J. D. Ventura, H. Wan, Y. Cai, B. Chen, A. G. Schmidt, D. R. Wesemann, R. S. Baric, G. Alter, H. Andersen, M. G. Lewis, D. H. Barouch, DNA vaccine protection against SARS-CoV-2 in rhesus macaques. Science 369 , 806-811 (2020). doi:10.1126/science.abc6284 Medline

27. A. Alrubayyi, A. Schuetz, K. G. Lal, S. Jongrakthaitae, K. M. Paolino, J. A. Ake, M. L. Robb, M. S. de Souza, N. L. Michael, D. Paquin-Proulx, M. A. Eller, A flow cytometry based assay that simultaneously measures cytotoxicity and monocyte mediated antibody dependent effector activity. J. Immunol. Methods 462, 74-82 (2018). doi:10.1016/i.jim.2018.08.012 Medline

28. B. F. Haynes, L. Corey, P. Fernandes, P. B. Gilbert, P. J. Hotez, S. Rao, M. R. Santos, H. Schuitemaker, M. Watson, A. Arvin, Prospects for a safe COVID-19 vaccine. Sci. Transl. Med. 12, eabe0948 (2020). doi:10.1126/scitranslmed.abe0948 Medline

29. J. S. Hale, R. Ahmed, Memory T follicular helper CD4 T cells. Front. Immunol. 6, 16 (2015). doi:10.3389/fimmu.2015.00016 Medline
30. Y. Liu, J. Liu, H. Xia, X. Zhang, C. R. Fontes-Garfias, K. A. Swanson, H. Cai, R. Sarkar, W. Chen, M. Cutler, D. Cooper, S. C. Weaver, A. Muik, U. Sahin, K. U. Jansen, X. Xie, P. R. Dormitzer, P.-Y. Shi, Neutralizing Activity of BNT162b2-Elicited Serum. N. Engl. J. Med. 384, 1466-1468 (2021). doi:10.1056/NEJMc2102017 Medline

31. X. Shen, H. Tang, C. McDanal, K. Wagh, W. Fischer, J. Theiler, H. Yoon, D. Li, B. F. Haynes, K. O. Sanders, S. Gnanakaran, N. Hengartner, R. Pajon, G. Smith, G. M. Glenn, B. Korber, D. C. Montefiori, SARS-CoV-2 variant B.1.1.7 is susceptible to neutralizing antibodies elicited by ancestral spike vaccines. Cell Host Microbe 29, 529-539.e3 (2021). doi:10.1016/i.chom.2021.03.002 Medline

32. M. Voysey, A. J. Pollard, ChAdOx1 nCoV-19 vaccine for SARS-CoV-2 - Authors' reply. Lancet 396, 1486-1487 (2020). doi:10.1016/S0140-6736(20)32267-4 Medline

33. Z. Wang, F. Schmidt, Y. Weisblum, F. Muecksch, C. O. Barnes, S. Finkin, D. Schaefer-Babajew, M. Cipolla, C. Gaebler, J. A. Lieberman, T. Y. Oliveira, Z. Yang, M. E. Abernathy, K. E. Huey-Tubman, A. Hurley, M. Turroja, K. A. West, K. Gordon, K. G. Millard, V. Ramos, J. Da Silva, J. Xu, R. A. Colbert, R. Patel, J. Dizon, C. UnsonO'Brien, I. Shimeliovich, A. Gazumyan, M. Caskey, P. J. Bjorkman, R. Casellas, T. Hatziioannou, P. D. Bieniasz, M. C. Nussenzweig, mRNA vaccine-elicited antibodies to SARS-CoV-2 and circulating variants. Nature 592, 616-622 (2021). doi:10.1038/s41586-021-03324-6 Medline

34. K. S. Corbett, B. Flynn, K. E. Foulds, J. R. Francica, S. Boyoglu-Barnum, A. P. Werner, B. Flach, S. O'Connell, K. W. Bock, M. Minai, B. M. Nagata, H. Andersen, D. R. Martinez, A. T. Noe, N. Douek, M. M. Donaldson, N. N. Nji, G. S. Alvarado, D. K. Edwards, D. R. Flebbe, E. Lamb, N. A. Doria-Rose, B. C. Lin, M. K. Louder, S. O'Dell, S. D. Schmidt, E. Phung, L. A. Chang, C. Yap, J. M. Todd, L. Pessaint, A. Van Ry, S. Browne, J. Greenhouse, T. Putman-Taylor, A. Strasbaugh, T.-A. Campbell, A. Cook, A. Dodson, K. Steingrebe, W. Shi, Y. Zhang, O. M. Abiona, L. Wang, A. Pegu, E. S. Yang, K. Leung, T. Zhou, I.-T. Teng, A. Widge, I. Gordon, L. Novik, R. A. Gillespie, R. J. Loomis, J. I. Moliva, G. Stewart-Jones, S. Himansu, W.-P. Kong, M. C. Nason, K. M. Morabito, T. J. Ruckwardt, J. E. Ledgerwood, M. R. Gaudinski, P. D. Kwong, J. R. Mascola, A. Carfi, M. G. Lewis, R. S. Baric, A. McDermott, I. N. Moore, N. J. Sullivan, M. Roederer, R. A. Seder, B. S. Graham, Evaluation of the mRNA1273 Vaccine against SARS-CoV-2 in Nonhuman Primates. N. Engl. J. Med. 383, 1544-1555 (2020). doi:10.1056/NEJMoa2024671 Medline

35. M. Guebre-Xabier, N. Patel, J.-H. Tian, B. Zhou, S. Maciejewski, K. Lam, A. D. Portnoff, M. J. Massare, M. B. Frieman, P. A. Piedra, L. Ellingsworth, G. Glenn, G. Smith, NVX-CoV2373 vaccine protects cynomolgus macaque upper and lower airways against SARS-CoV-2 challenge. Vaccine 38, 7892-7896 (2020). doi:10.1016/i.vaccine.2020.10.064 Medline

36. H. Wang, Y. Zhang, B. Huang, W. Deng, Y. Quan, W. Wang, W. Xu, Y. Zhao, N. Li, J. Zhang, H. Liang, L. Bao, Y. Xu, L. Ding, W. Zhou, H. Gao, J. Liu, P. Niu, L. Zhao, W. Zhen, H. Fu, S. Yu, Z. Zhang, G. Xu, C. Li, Z. Lou, M. Xu, C. Qin, G. Wu, G. F. Gao, W. Tan, X. Yang, Development of an Inactivated Vaccine Candidate, BBIBP-CorV, with Potent Protection against SARS-CoV-2. Cell 182, 713-721.e9 (2020). doi:10.1016/i.cell.2020.06.008 Medline

37. N. van Doremalen, T. Lambe, A. Spencer, S. Belij-Rammerstorfer, J. N. Purushotham, J. R. Port, V. A. Avanzato, T. Bushmaker, A. Flaxman, M. Ulaszewska, F. Feldmann, E. R. Allen, H. Sharpe, J. Schulz, M. Holbrook, A. Okumura, K. Meade-White, L. Pérez-Pérez, N. J. Edwards, D. Wright, C. Bissett, C. Gilbride, B. N. Williamson, R. Rosenke, D. Long, A. Ishwarbhai, R. Kailath, L. Rose, S. Morris, C. Powers, J. Lovaglio, P. W. Hanley, D. Scott, G. Saturday, E. de Wit, S. C. Gilbert, V. J. Munster, ChAdOx1nCoV-19 vaccine prevents SARS-CoV-2 pneumonia in rhesus macaques. Nature 586, 578-582 (2020). doi:10.1038/s41586-020-2608-y Medline

38. A. B. Vogel, I. Kanevsky, Y. Che, K. A. Swanson, A. Muik, M. Vormehr, L. M. Kranz, K. C. Walzer, S. Hein, A. Güler, J. Loschko, M. S. Maddur, A. Ota-Setlik, K. Tompkins, J. Cole, B. G. Lui, T. Ziegenhals, A. Plaschke, D. Eisel, S. C. Dany, S. Fesser, S. Erbar, F. Bates, D. Schneider, B. Jesionek, B. Sänger, A. K. Wallisch, Y. Feuchter, H. Junginger, S. A. Krumm, A. P. Heinen, P. Adams-Quack, J. Schlereth, S. Schille, C. Kröner, R. de la Caridad Güimil Garcia, T. Hiller, L. Fischer, R. S. Sellers, S. Choudhary, O. Gonzalez, F. Vascotto, M. R. Gutman, J. A. Fontenot, S. Hall-Ursone, K. Brasky, M. C. Griffor, S. Han, A. A. H. Su, J. A. Lees, N. L. Nedoma, E. H. Mashalidis, P. V. Sahasrabudhe, C. Y. Tan, D. Pavliakova, G. Singh, C. FontesGarfias, M. Pride, I. L. Scully, T. Ciolino, J. Obregon, M. Gazi, R. Carrion Jr., K. J. Alfson, W. V. Kalina, D. Kaushal, P.-Y. Shi, T. Klamp, C. Rosenbaum, A. N. Kuhn, Ö. 
Türeci, P. R. Dormitzer, K. U. Jansen, U. Sahin, BNT162b vaccines protect rhesus macaques from SARS-CoV-2. Nature 592, 283-289 (2021). doi:10.1038/s41586021-03275-y Medline

39. J. Verma, N. Subbarao, A comparative study of human betacoronavirus spike proteins: Structure, function and therapeutics. Arch. Virol. 166, 697-714 (2021). doi:10.1007/s00705-021-04961-y Medline

40. J. Li, L. Ulitzky, E. Silberstein, D. R. Taylor, R. Viscidi, Immunogenicity and protection efficacy of monomeric and trimeric recombinant SARS coronavirus spike protein subunit vaccine candidates. Viral Immunol. 26, 126-132 (2013). doi:10.1089/vim.2012.0076 Medline

41. R. L. Roper, K. E. Rehm, SARS vaccines: Where are we? Expert Rev. Vaccines 8 , 887-898 (2009). doi:10.1586/erv.09.43 Medline

42. A. M. Sholukh, A. Fiore-Gartland, E. S. Ford, M. D. Miner, Y. J. Hou, L. V. Tse, H. Kaiser, H. Zhu, J. Lu, B. Madarampalli, A. Park, F. A. Lempp, R. St Germain, E. L. Bossard, J. J. Kee, K. Diem, A. B. Stuart, P. B. Rupert, C. Brock, M. Buerger, M. K. Doll, A. K. Randhawa, L. Stamatatos, R. K. Strong, C. McLaughlin, M. L. Huang, K. R. Jerome, R. S. Baric, D. Montefiori, L. Corey, Evaluation of Cell-Based and Surrogate SARS-CoV-2 Neutralization Assays. J. Clin. Microbiol. 59, e0052721 (2021). doi:10.1128/JCM.00527-21 Medline

43. M. Voysey, S. A. C. Clemens, S. A. Madhi, L. Y. Weckx, P. M. Folegatti, P. K. Aley, B. Angus, V. L. Baillie, S. L. Barnabas, Q. E. Bhorat, S. Bibi, C. Briner, P. Cicconi, A. M. Collins, R. Colin-Jones, C. L. Cutland, T. C. Darton, K. Dheda, C. J. A. Duncan, K. R. W. Emary, K. J. Ewer, L. Fairlie, S. N. Faust, S. Feng, D. M. Ferreira, A. Finn, A. L. Goodman, C. M. Green, C. A. Green, P. T. Heath, C. Hill, H. Hill, I. Hirsch, S. H. C. Hodgson, A. Izu, S. Jackson, D. Jenkin, C. C. D. Joe, S. Kerridge, A. Koen, G. Kwatra, R. Lazarus, A. M. Lawrie, A. Lelliott, V. Libri, P. J. Lillie, R. Mallory, A. V. A. Mendes, E. P. Milan, A. M. Minassian, A. McGregor, H. Morrison, Y. F. Mujadidi, A. Nana, P. J. O'Reilly, S. D. Padayachee, A. Pittella, E. Plested, K. M. Pollock, M. N. Ramasamy, S. Rhead, A. V. Schwarzbold, N. Singh, A. Smith, R. Song, M. D. Snape, E. Sprinz, R. K. Sutherland, R. Tarrant, E. C. Thomson, M. E. Török, M. Toshner, D. P. J. Turner, J. Vekemans, T. L. Villafana, M. E. E. Watson, C. J. Williams, A. D. Douglas, A. V. S. Hill, T. Lambe, S. C. Gilbert, A. J. Pollard; Oxford COVID Vaccine Trial Group, Safety and efficacy of the ChAdOx1 nCoV-19 vaccine (AZD1222) against SARS-CoV-2: An interim analysis of four randomised controlled trials in Brazil, South Africa, and the UK. Lancet 397, 99-111 (2021). doi:10.1016/S01406736(20)32661-1 Medline

44. J. E. Staples, A. D. T. Barrett, A. Wilder-Smith, J. Hombach, Review of data and knowledge gaps regarding yellow fever vaccine-induced immunity and duration of protection. NPJ Vaccines 5, 54 (2020). doi:10.1038/s41541-020-0205-6 Medline

45. S. N. Crooke, M. M. Riggenbach, I. G. Ovsyannikova, N. D. Warner, M.-H. Chen, L. Hao, J. P. Icenogle, G. A. Poland, R. B. Kennedy, Durability of humoral immune responses to rubella following MMR vaccination. Vaccine 38, 8185-8193 (2020). doi:10.1016/i.vaccine.2020.10.076 Medline

46. H. Theeten, K. Van Herck, O. Van Der Meeren, P. Crasta, P. Van Damme, N. Hens, Long-term antibody persistence after vaccination with a 2-dose Havrix (inactivated hepatitis A vaccine): 20 years of observed data, and long-term model-based predictions. Vaccine 33, 5723-5727 (2015). doi:10.1016/i.vaccine.2015.07.008 Medline

47. A. A. Cohen, P. N. P. Gnanapragasam, Y. E. Lee, P. R. Hoffman, S. Ou, L. M. Kakutani, J. R. Keeffe, H.-J. Wu, M. Howarth, A. P. West, C. O. Barnes, M. C. Nussenzweig, P. J. Bjorkman, Mosaic nanoparticles elicit cross-reactive immune responses to zoonotic coronaviruses in mice. Science 371, 735-741 (2021). doi:10.1126/science. abf6840 Medline

48. A. E. Powell, K. Zhang, M. Sanyal, S. Tang, P. A. Weidenbacher, S. Li, T. D. Pham, J. E. Pak, W. Chiu, P. S. Kim, A Single Immunization with Spike-Functionalized Ferritin Vaccines Elicits Neutralizing Antibody Responses against SARS-CoV-2 in Mice. ACS Cent. Sci. 7, 183-199 (2021). doi:10.1021/acscentsci.0c01405 Medline

49. K. O. Saunders, E. Lee, R. Parks, D. R. Martinez, D. Li, H. Chen, R. J. Edwards, S. Gobeil, M. Barr, K. Mansouri, S. M. Alam, L. L. Sutherland, F. Cai, A. M. Sanzone, M. Berry, K. Manne, K. W. Bock, M. Minai, B. M. Nagata, A. B. Kapingidza, M. Azoitei, L. V. Tse, T. D. Scobey, R. L. Spreng, R. W. Rountree, C. T. DeMarco, T. N. Denny, C. W. Woods, E. W. Petzold, J. Tang, T. H. Oguin 3rd, G. D. Sempowski, M. Gagne, D. C. Douek, M. A. Tomai, C. B. Fox, R. Seder, K. Wiehe, D. Weissman, N. Pardi, H. Golding, S. Khurana, P. Acharya, H. Andersen, M. G. Lewis, I. N. Moore, D. C. Montefiori, R. S. Baric, B. F. Haynes, Neutralizing antibody vaccine for pandemic and pre-emergent coronaviruses. Nature 594, 553-559 (2021). doi:10.1038/s41586-021-03594-0 Medline

50. C. J. Genito, Z. Beck, T. W. Phares, F. Kalle, K. J. Limbach, M. E. Stefaniak, N. B. Patterson, E. S. Bergmann-Leitner, N. C. Waters, G. R. Matyas, C. R. Alving, S. Dutta, Liposomes containing monophosphoryl lipid A and QS-21 serve as an effective adjuvant for soluble circumsporozoite protein malaria vaccine FMP013. Vaccine 35, 3865-3874 (2017). doi:10.1016/i.vaccine.2017.05.070 Medline

51. A. Ramakrishnan, N. M. Schumack, C. L. Gariepy, H. Eggleston, G. Nunez, N. Espinoza, M. Nieto, R. Castillo, J. Rojas, A. J. McCoy, Z. Beck, G. R. Matyas, C. R. Alving, P. Guerry, F. Poly, R. M. Laird, Enhanced Immunogenicity and Protective Efficacy of a Campylobacter jejuni Conjugate Vaccine Coadministered with Liposomes Containing Monophosphoryl Lipid A and QS-21. MSphere 4 (2019). doi:10.1128/mSphere.00101-19

52. K. M. Wuertz, E. K. Barkei, W.-H. Chen, E. J. Martinez, I. Lakhal-Naouar, L. L. Jagodzinski, D. Paquin-Proulx, G. D. Gromowski, I. Swafford, A. Ganesh, M. Dong, X. Zeng, P. V. Thomas, R. S. Sankhala, A. Hajduczki, C. E. Peterson, C. Kuklis, S. Soman, L. Wieczorek, M. Zemil, A. Anderson, J. Darden, H. Hernandez, H. Grove, V. Dussupt, H. Hack, R. de la Barrera, S. Zarling, J. F. Wood, J. W. Froude, M. Gagne, A. R. Henry, E. B. Mokhtari, P. Mudvari, S. J. Krebs, A. S. Pekosz, J. R. Currier, S. Kar, M. Porto, A. Winn, K. Radzyminski, M. G. Lewis, S. Vasan, M. Suthar, V. R. Polonis, G. R. Matyas, E. A. Boritz, D. C. Douek, R. A. Seder, S. P. Daye, M. Rao, S. A. Peel, M. G. Joyce, D. L. Bolton, N. L. Michael, K. Modjarrad, A SARS-CoV-2 spike ferritin nanoparticle vaccine protects hamsters against Alpha and Beta virus variant challenge. NPJ Vaccines 6, 129 (2021). doi:10.1038/s41541-021-00392-7 Medline

53. clinicaltrials.gov, (2) $=$ paul + scott\&draw $=2$ \&rank=1, 2021)

54. P. Singh, Z. Beck, G. R. Matyas, C. R. Alving, Saturated phospholipids are required for nano- to micron-size transformation of cholesterol-containing liposomes upon QS21 addition. J. Liposome Res. 29, 247-250 (2019). doi:10.1080/08982104.2018.1538239 Medline

55. E. K. Nelson, B. Piehler, J. Eckels, A. Rauch, M. Bellew, P. Hussey, S. Ramsay, C. Nathe, K. Lum, K. Krouse, D. Stearns, B. Connolly, T. Skillman, M. Igra, LabKey Server: An open source platform for scientific data integration, analysis and collaboration. BMC Bioinformatics 12, 71 (2011). doi:10.1186/1471-2105-12-71 Medline

56. L. Liu, P. Wang, M. S. Nair, J. Yu, M. Rapp, Q. Wang, Y. Luo, J. F.-W. Chan, V. Sahi, A. Figueroa, X. V. Guo, G. Cerutti, J. Bimela, J. Gorman, T. Zhou, Z. Chen, K.-Y. Yuen, P. D. Kwong, J. G. Sodroski, M. T. Yin, Z. Sheng, Y. Huang, L. Shapiro, D. D. $\mathrm{Ho}$, Potent neutralizing antibodies against multiple epitopes on SARS-CoV-2 spike. Nature 584, 450-456 (2020). doi:10.1038/s41586-020-2571-7 Medline

57. P. Wang, L. Liu, M. S. Nair, M. T. Yin, Y. Luo, Q. Wang, T. Yuan, K. Mori, A. G. Solis, M. Yamashita, A. Garg, L. J. Purpura, J. C. Laracy, J. Yu, L. Joshua-Tor, J. Sodroski, Y. Huang, D. D. Ho, SARS-CoV-2 neutralizing antibody responses are more robust in patients with severe disease. Emerg. Microbes Infect. 9, 2091-2093 (2020). doi:10.1080/22221751.2020.1823890 Medline

58. K. T. Abe, Z. Li, R. Samson, P. Samavarchi-Tehrani, E. J. Valcourt, H. Wood, P. Budylowski, A. P. Dupuis 2nd, R. C. Girardin, B. Rathod, J. H. Wang, M. BarriosRodiles, K. Colwill, A. J. McGeer, S. Mubareka, J. L. Gommerman, Y. Durocher, M. Ostrowski, K. A. McDonough, M. A. Drebot, S. J. Drews, J. M. Rini, A.-C. Gingras, A simple protein-based surrogate neutralization assay for SARS-CoV-2. JCl Insight 5, e142362 (2020). doi:10.1172/jci.insight.142362 Medline

59. S. Fischinger, J. K. Fallon, A. R. Michell, T. Broge, T. J. Suscovich, H. Streeck, G. Alter, A high-throughput, bead-based, antigen-specific assay to assess the ability of antibodies to induce complement activation. J. Immunol. Methods 473, 112630 (2019). doi:10.1016/i.jim.2019.07.002 Medline

60. L. Ninove, A. Nougairede, C. Gazin, L. Thirion, I. Delogu, C. Zandotti, R. N. Charrel, $X$. De Lamballerie, RNA and DNA bacteriophages as molecular diagnosis controls in clinical virology: A comprehensive study of more than 45,000 routine PCR tests. PLOS ONE 6, e16142 (2011). doi:10.1371/journal.pone.0016142 Medline

Acknowledgments: We thank J. Lay, E. Zografos, J. Lynch, L. Mendez-Rivera, N. Jackson, B. Slike, U. Tran, S. Peters, J. Bolton, T. Robinson, E. Duncan, H. Siegfried, R.J. O'Connell, Z. Beck and C. Alving for technical support, assistance, and advice. Funding: We acknowledge support from the U.S. Department of 
Defense, Defense Health Agency (Restoral FY20 to KM). This work was partially executed through a cooperative agreement between the U.S. Department of Defense and the Henry M. Jackson Foundation for the Advancement of Military Medicine, Inc. (W81XWH-18-2-0040). The views expressed are those of the authors and should not be construed to represent the positions of the U.S. Army or the Department of Defense. Author contributions: K.M. and M.G.J designed the study. I.E.N, A.A., K.K.P., C.M.C., C.S., R.E.C, J.B.C., P.V.T., W-H.C., R.S.S., A.H., E.J.M., C.E.P., W.C.C., M.C., C.S., P.J.L., A.A., K.M.W., M.S.N., H.M.S., N.dV., M.D., I.S., J.R.C., K.G.L, V.D., S.M., K.A., R.C., S.J.K. D.P.P., N.K., V.R.P., Y.H., L.L.J., G.D.G. performed immunologic and virologic assays. H.A.E, A.C., M.G.L. led the clinical care of the animals. S.P.D., X.Z., E.K.D performed histopathology. K.M., M.G.J., P.V.T., W-H.C., R.S.S., A.H., E.J.M., C.E.P., W.C.C., and M.C. designed the immunogens. M.R., G.R.M., and A.A. designed and provided the adjuvant. M.G.J., H.A.D.K. J.A.H., S.P.D., M.F.A., S.V., P.T.S., D.D.H., M.S.D., M.G.L., M.R., G.D.G., S.A.P., N.L.M. D.L.B. and K.M. analyzed and interpreted the data. K.M. wrote the paper with assistance from all coauthors. Competing interests: K.M. and M.G.J. are primary co-inventors on related vaccine patents (U.S. Provisional Application 62/986,522 filed March 6, 2020, and to U.S. Provisional Application 63/038,600 filed June 12, 2020). M.S.D. is a consultant for Inbios, Vir Biotechnology, Fortress Biotech, and Carnival Corporation. The Diamond laboratory has received unrelated funding support in sponsored research agreements from Moderna, Vir Biotechnology, and Emergent BioSolutions. M.S.D. is on the Scientific Advisory Boards of Moderna and Immunome. The other authors declare no competing interests. Data and materials availability: All data are available in the manuscript or the supplementary materials. The vaccine and adjuvant used in this study will be made available to the scientific community by contacting Kayvon Modjarrad and completion of a materials transfer agreement. This work is licensed under a Creative Commons Attribution 4.0 International (CC BY 4.0) license, which permits unrestricted use, distribution, and reproduction in any medium, provided the original work is properly cited. To view a copy of this license, visit https://creativecommons.org/licenses/by/4.0/. This license does not apply to figures/photos/artwork or other content included in the article that is credited to a third party; obtain authorization from the rights holder before using this material.

Submitted 17 March 2021

Accepted 8 December 2021

Published First Release 16 December 2021

10.1126/scitransImed.abi5735 
A

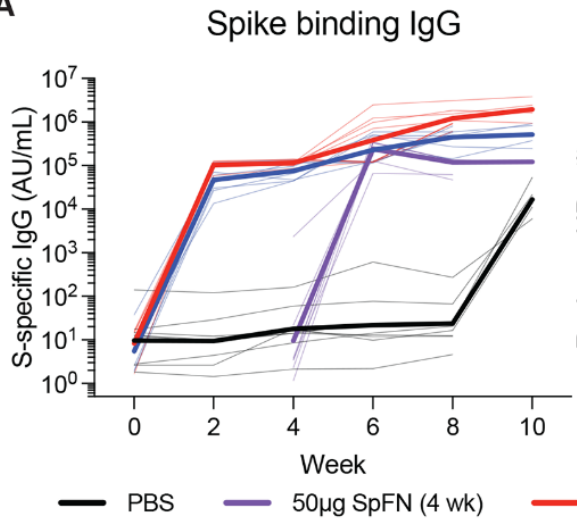

C

Live virus neutralization at week 8

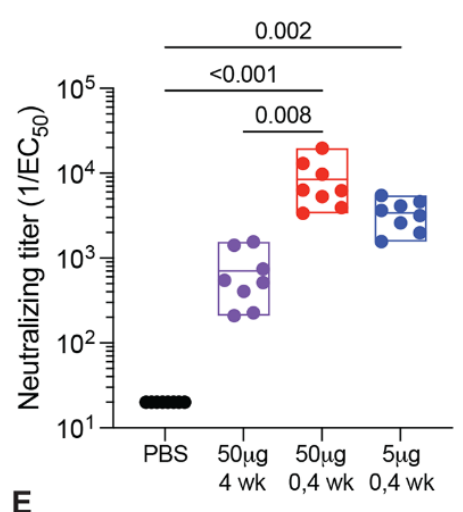

Pseudovirus neutralization at week 8

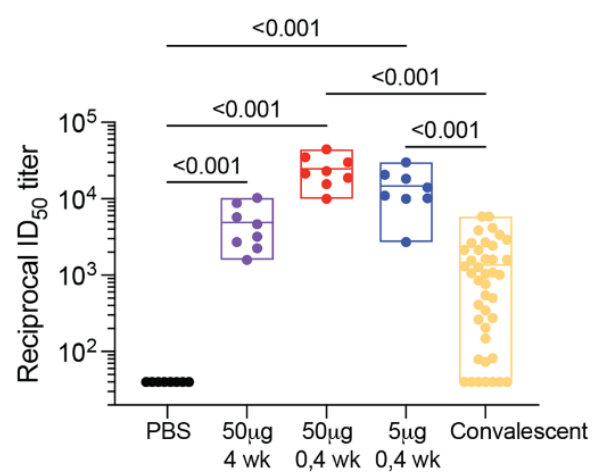

B Pseudovirus neutralization

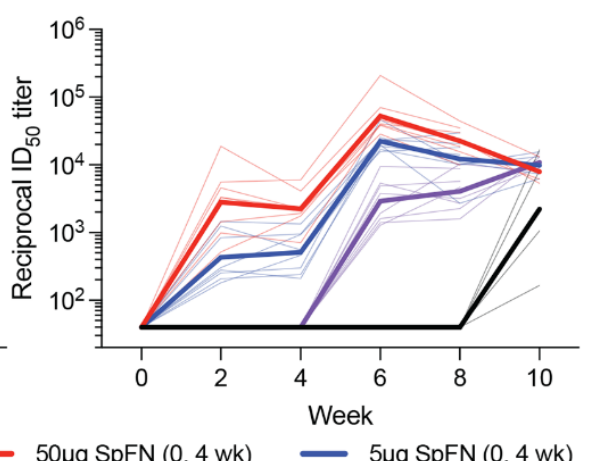

D ACE2 Inhibition at week 8

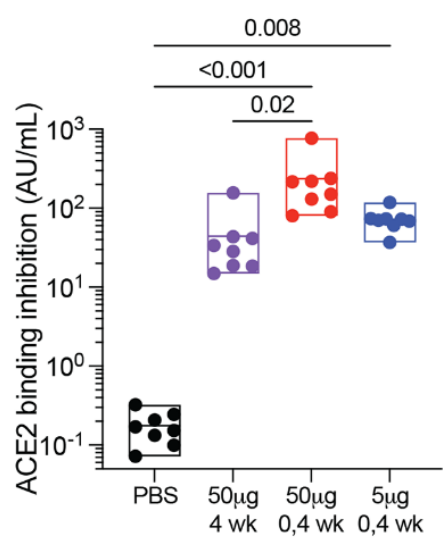




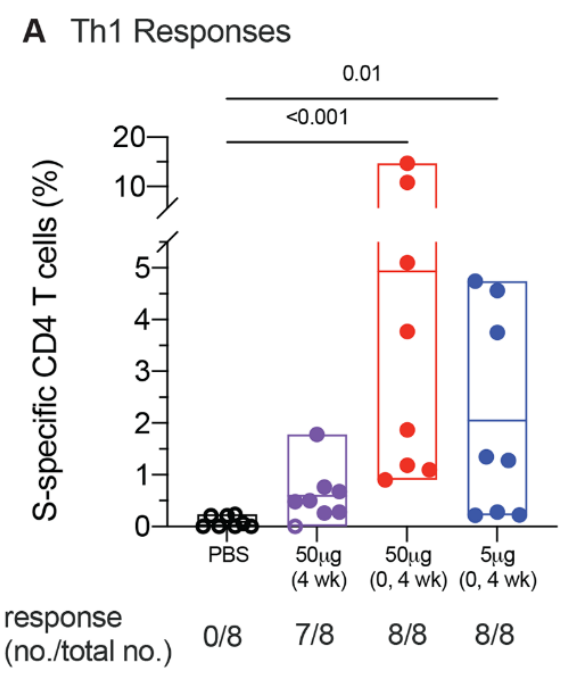

C IL-21

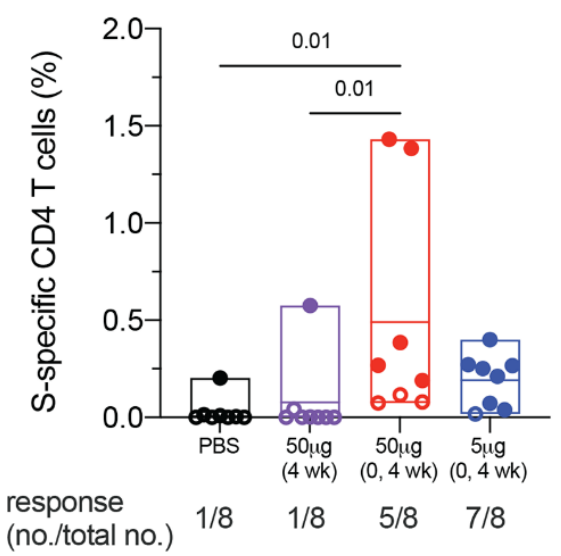

B Th2 Responses

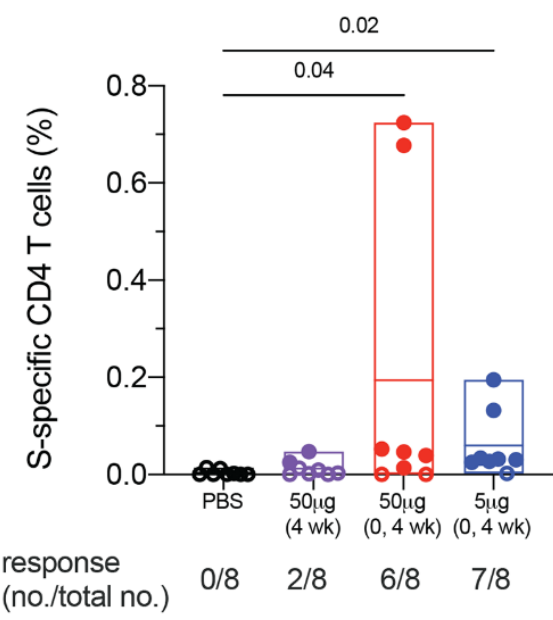

D CD40L

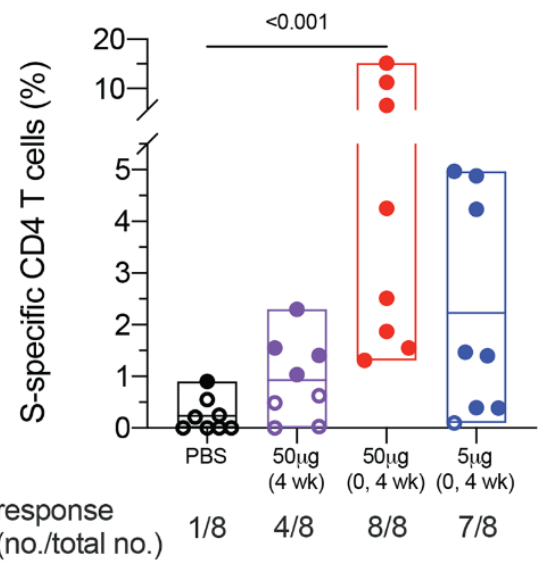

Fig. 2. SpFN vaccination elicited SARS-CoV-2 spike protein-specific CD4 T cell responses in rhesus macaques. T cell responses were assessed by SARS-CoV-2 spike peptide pool stimulation and intracellular cytokine staining of peripheral blood mononuclear cells collected at 4 weeks after last vaccination. Spike protein-specific memory CD4 T cells expressing the indicated markers are shown as follows: (A) Th1 cytokines (IFN- $\gamma$, TNF and IL-2); (B) Th2 cytokines (IL-4 and IL-13); (C) IL21; (D) and CD4OL. Boolean combinations of cytokine positive memory CD4 T cells were summed. Probable positive responses, defined as greater than 3 times the group background at baseline, are depicted as closed symbols. Positivity rates within each group are shown below each graph as a fraction. In the box plots, horizontal lines indicate the mean and the top and bottom reflect the minimum and maximum. Significance was assessed using a Kruskal-Wallis test followed by a Dunn's post-test. Only statistically significant differences at $\alpha=0.05$ are presented. 


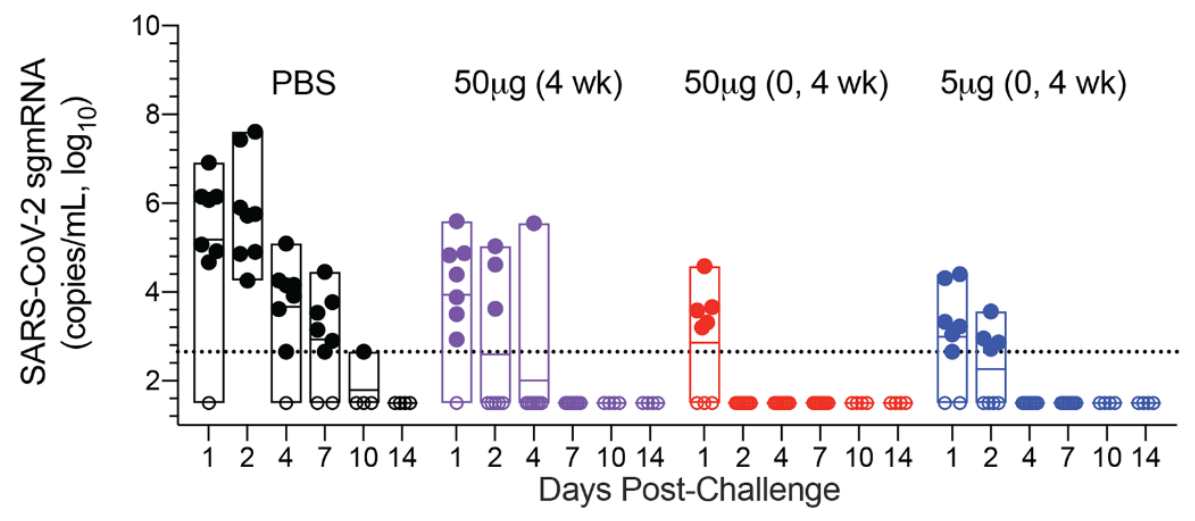

B

NP Swabs

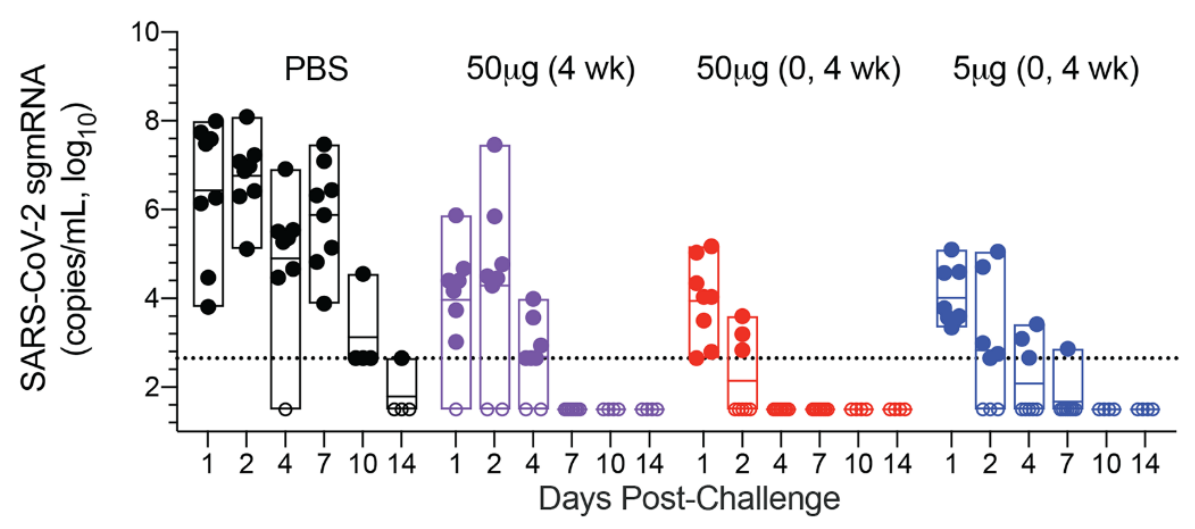

C

Saliva

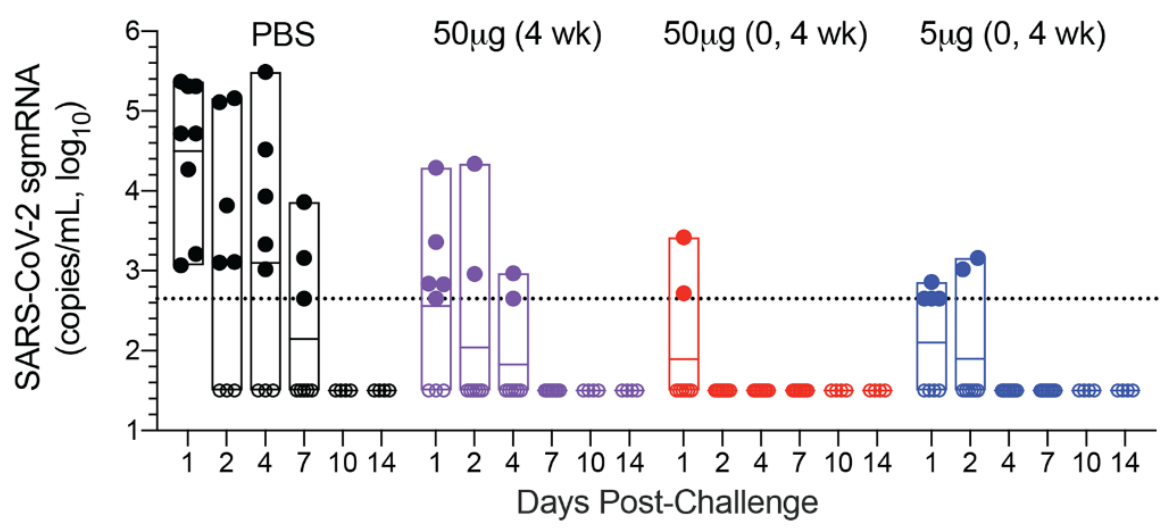

Fig. 3. Viral replication was reduced in the lower and upper airways after $\mathrm{SpFN}$ vaccination and subsequent SARS-CoV-2 respiratory challenge. Subgenomic messenger RNA (sgmRNA) copies per milliliter were measured in the (A) bronchoalveolar lavage fluid, (B) nasopharyngeal swabs and (C) saliva of vaccinated and control animals for two weeks following intranasal and intratracheal SARS-CoV-2 (USA-WA1/2020) challenge. Specimens were collected on 1, 2, 4, 7, 10 and 14 days post-challenge. Dotted lines demarcate assay lower limits of linear performance range (to 450 copies $/ \mathrm{ml}$ ). In the box plots, horizontal lines indicate the mean and the top and bottom reflect the minimum and maximum. 


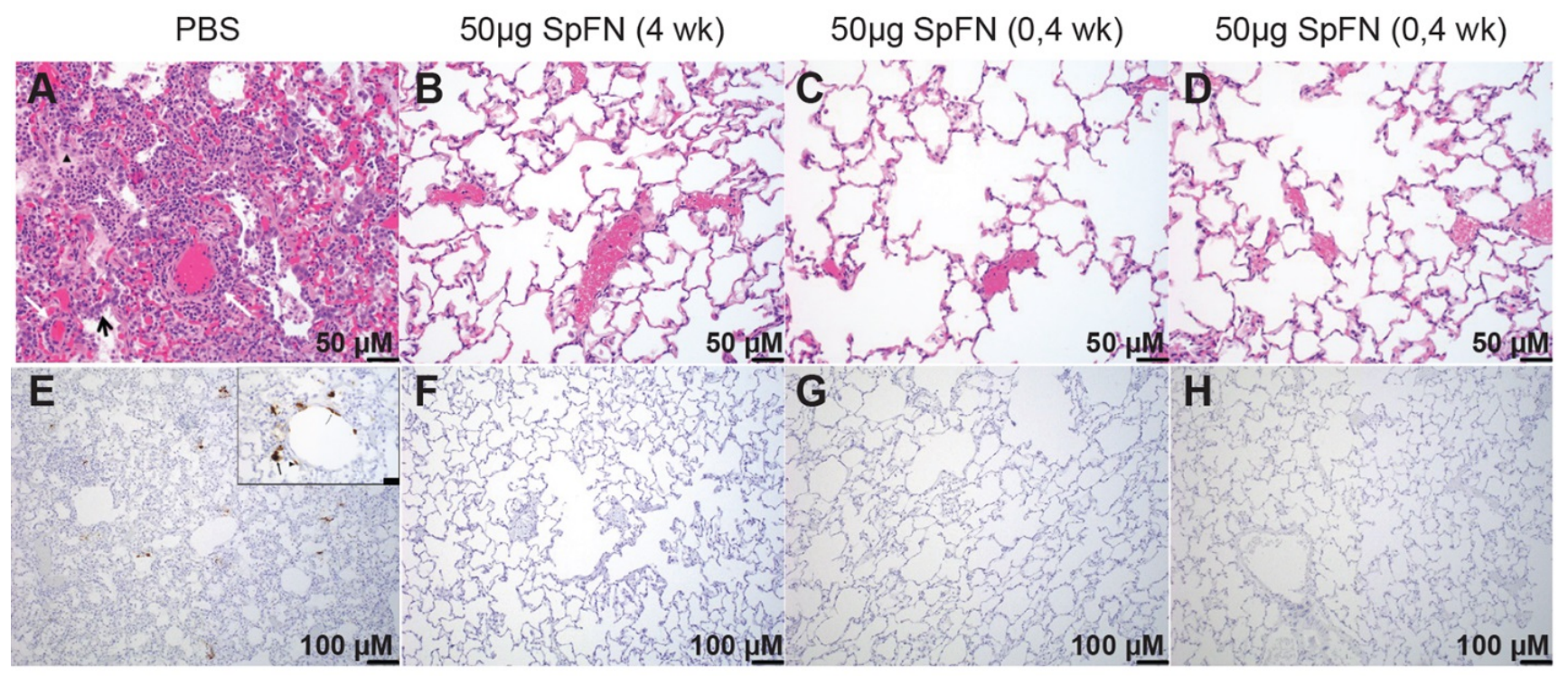

Fig. 4. Histopathology and virus detection in the lungs of SpFN vaccinated and unvaccinated control rhesus macaques following SARS-CoV-2 respiratory challenge. (A to D) Paraffinembedded lung parenchymal tissue sections collected at 7 days post-challenge were stained with hematoxylin and eosin (H\&E). (E to $\mathrm{H}$ ) samples were also used for $\mathrm{IHC}$ to measure viral antigen (brown). Representative images at two different magnifications, one for H\&E and the other for $\mathrm{IHC}$, are presented. The symbols (A) show pulmonary macrophages infiltrate. Viral antigen is seen as brown aggregates with an inset at higher magnification $(20 \mu \mathrm{m})$ showing peribronchiolar virus identified with arrows and arrowheads (E). 


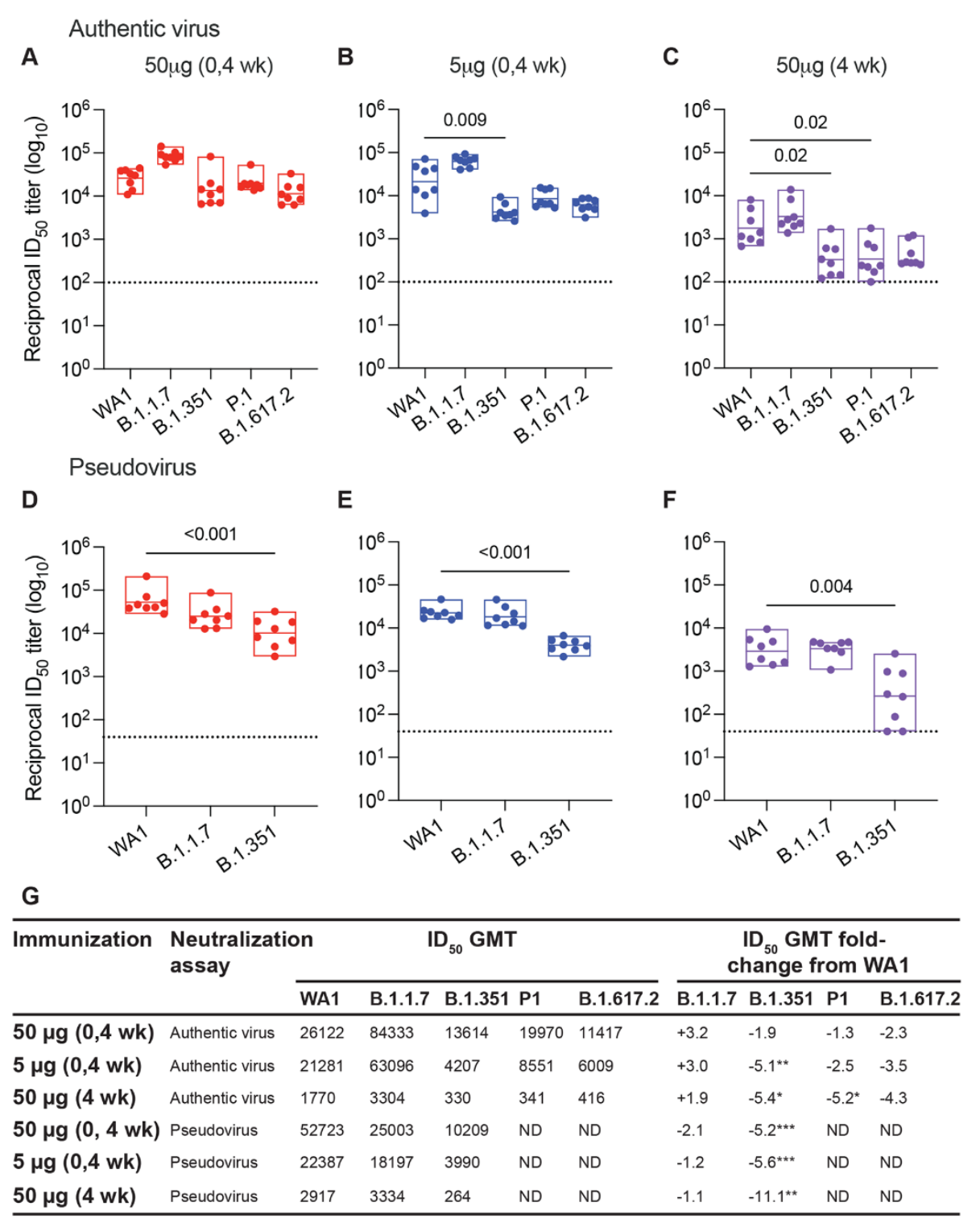

Fig. 5. Neutralizing antibody responses are elicited against SARS-CoV-2 variants B.1.1.7, B.1.351, P.1, and B.1.617.2 by SpFN vaccination in rhesus macaques. (A to $C$ ) Authentic virus and ( $D$ to $F$ ) pseudovirus neutralizing antibody responses were measured 2 weeks after last SpFN vaccination with either two doses of $50 \mu g(A, D)$ or $5 \mu g$ $(B, E)$ or one dose of $50 \mu \mathrm{g}(\mathrm{C}, \mathrm{F})$. (G) Reciprocal ID $50 \mathrm{GMT}$ against each variant of concern and fold-change from wildtype neutralization (WA-1 or Wuhan-1) were assessed. Statistically significant fold-change differences are indicated as follows: ${ }^{*} p<0.05$; ${ }^{* *} p<0.01$; and ${ }^{* * *} p<0.001$. Statistical comparisons were done by Kruskal-Wallis test followed by a Dunn's post-test. In the box plots, horizontal lines indicate the geometric mean and the top and bottom reflect the minimum and maximum. Dotted lines indicate lower limit of detection. Only statistically significant differences at $\alpha=0.05$ are presented in the graphs. 
A

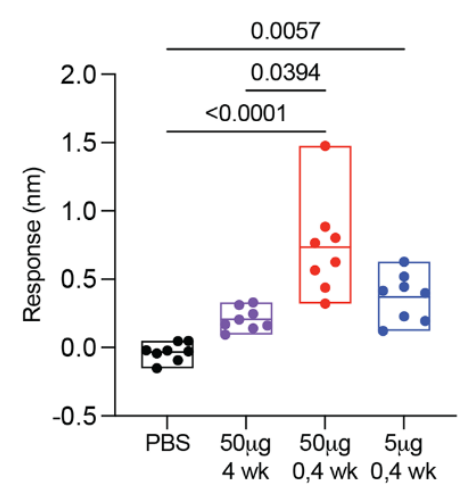

C

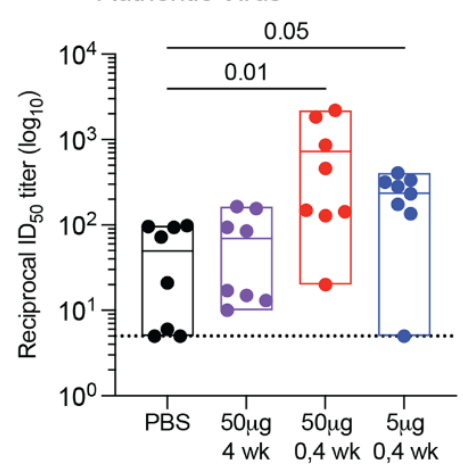

E

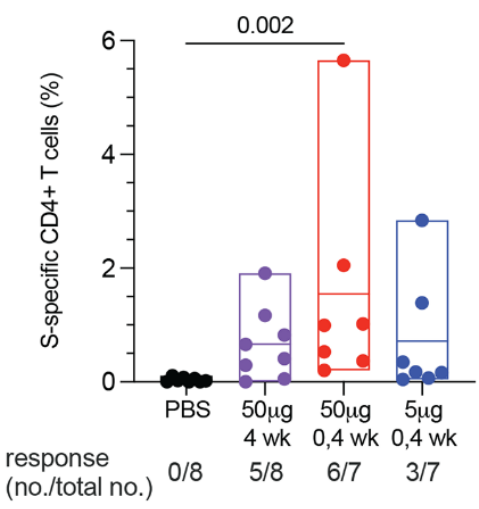

B $\quad$ ADCP

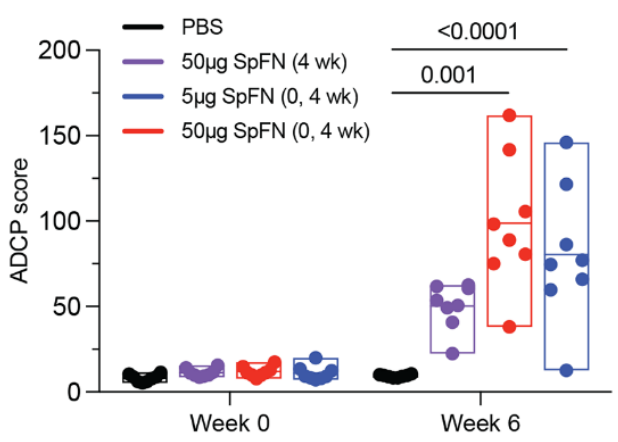

D Pseudovirus

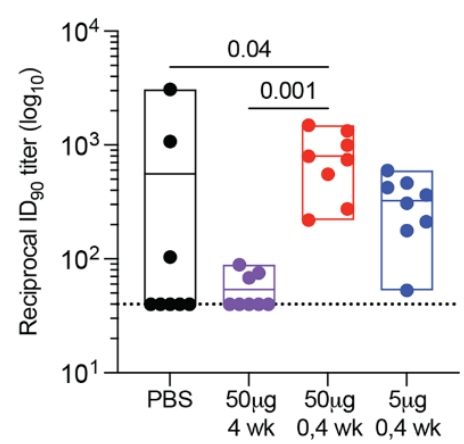

F Th2 Responses

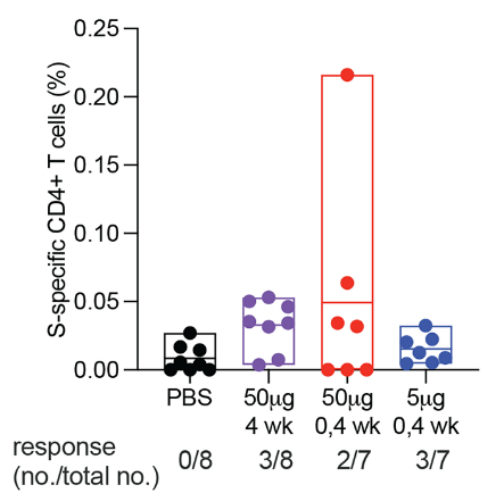

Fig. 6. Humoral and Cellular Immune Responses to SARS-CoV-1 are elicited by SpFN vaccination of Rhesus Macaques. (A) Serum binding responses to SARS-CoV-1 RBD were measured by biolayer interferometry. (B) Antibody dependent cellular phagocytosis induction by serum samples was measured. (C and D) Serum samples were tested for neutralization (ID 50 ) of authentic SARS-CoV-1 (Urbani) (C) and for pseudo-SARS-CoV-1 (Urbani) neutralization (ID90) (D). (E and F) SARS-CoV-1 (Urbani) spike protein-specific CD4 Th1 (E) and Th2 (F) responses were measured using PBMCs isolated 2 weeks after last vaccination (week 6). The fraction of animals exhibiting a Th1 or Th2 response are shown below each plot. Statistical significance was assessed with a KruskalWallis test followed by a Dunn's post-test. In the box plots, horizontal lines indicate the mean and the top and bottom reflect the minimum and maximum. Only statistically significant differences at $\alpha=0.05$ are presented in the graphs. 